\title{
Biodegradation of Naphthalene Using Glass Beads Roller Bioreactor: Application of Artificial Neural Network Modeling
}

\author{
Sinan J. Mohammed \\ Imam Sadiq University \\ yasmen mustafa ( $\sim$ yasmen.mustafa@gmail.com ) \\ Imam Ja'afar Al-Sadiq University https://orcid.org/0000-0002-4657-1840 \\ Mohanad S. Jabbar \\ Imam Ja'afar Al-Sadiq University
}

\section{Research Article}

Keywords: Roller bioreactor, Sewage waste sludge, Dissolution, Naphthalene, Artificial neural network

Posted Date: August 9th, 2021

DOl: https://doi.org/10.21203/rs.3.rs-731427/v1

License: (1) This work is licensed under a Creative Commons Attribution 4.0 International License.

Read Full License

Version of Record: A version of this preprint was published at Environmental Processes on February 26th, 2022. See the published version at https://doi.org/10.1007/s40710-022-00559-x. 


\title{
Biodegradation of naphthalene using glass beads roller bioreactor: application of artificial neural network modeling
}

\author{
Sinan J. Mohammed ${ }^{1}$, Yasmen A. Mustafa ${ }^{1 *}$, Mohanad S. Jabbar ${ }^{1}$ \\ ${ }^{1}$ Department of Economics of Oil and Gas, University of Imam Jaafar Al-Sadiq, Baghdad, Iraq \\ *Corresponding author \\ Email: yasmen.mustafa@gmail.com
}

\begin{abstract}
A roller bioreactor containing inert glass beads was employed to enhance naphthalene biodegradation in an aqueous solution. Mixed culture of microorganisms was isolated from sewage waste sludge and adopted for naphthalene biodegradation. The biodegradation of $300 \mathrm{mg} / \mathrm{L}$ naphthalene in the bioreactor with no glass beads proceeded slowly until depletion after seven days. In the presence of glass beads, the biodegradation rate was faster; it depleted after four days. The biodegradation rate of naphthalene was equal to $1.99 \mathrm{mgL}^{-}$ ${ }^{1} \mathrm{hr}^{-1}$ for bioreactor with no beads, while it is equal to 5.42, and $5.54 \mathrm{mgL}^{-1} \mathrm{hr}^{-1}$ for bioreactor with $40 \%$ load, $6 \mathrm{~mm}$ size and $50 \%$ load, $5 \mathrm{~mm}$ size of glass beads, respectively. For $500 \mathrm{mg} / \mathrm{L}$ naphthalene, nine days on the bioreactor with no glass beads and five days on glass beads bioreactors were required to complete depletion. The biodegradation rate is equal to $2.33,7.29$, and $7.85 \mathrm{mg} / \mathrm{L}^{-1} \mathrm{hr}^{-1}$ for bioreactors with no glass beads, $40 \%$ load with $6 \mathrm{~mm}$, and $50 \%$ load with $5 \mathrm{~mm}$ glass beads, respectively.

The specific growth rate $\mu$ was increased in the bioreactor with glass beads; it represents $0.031,0.050$, and $0.054 \mathrm{hr}^{-1}$ for $300 \mathrm{mg} / \mathrm{L}$ and $0.043,0.061$, and $0.065 \mathrm{hr}^{-1}$ for $500 \mathrm{mg} / \mathrm{L}$ respectively for the previously mentioned conditions. An artificial neural network was used to model naphthalene dissolution and biodegradation. A correlation coefficient of $99.2 \%$ and $98.3 \%$ were obtained between the experimental and predicted output values for dissolution and biodegradation, respectively, indicating that the ANN model could efficiently predict the experimental results. Time represents the most influential parameter on the dissolution and biodegradation treatment.
\end{abstract}

\section{Highlight}

- A roller bioreactor with inert glass beads was used to enhance the naphthalene biodegredation.

- The mixed culture of organisms was isolated from sewage waste sludge and adopted for naphthalene biodegradation.

- An artificial neural network (ANN) was used to model the biodegradation process.

Keywords Roller bioreactor. Sewage waste sludge. Dissolution. Naphthalene. Artificial neural network 


\section{Introduction}

Polycyclic aromatic hydrocarbons (PAHs) are hazardous aromatic compounds that consist of two or more fused benzene rings arranged in linear, angular, or cluster orientations. Naphthalene represents the simplest and most biodegradable compound of these PAHs. It contained two fused aromatic rings. It is abundantly found with other complex PAH compounds due to natural degradation processes (Reddy et al. 2002). The presence of PAHs in the en

vironment has been monitored by the US Environmental Protection Agency (USEPA) since the 1970s. Among these PAHs, 16 have been identified as High Priority Pollutants; they are of environmental concern due to their possible human carcinogens and their potential toxicity to higher forms of life. Naphthalene among these 16 PAHs (ATSDR, 2005). PAHs are highly recalcitrant, and because of their hydrophobicity, they have limited solubility in water which strengths their prevalence and persistence in the environment. PAHs contamination are widely distributed near industrial activities, especially the petroleum refineries. PAHs are commonly found in soils and aquatic sites (Bojes and Pope 2007; Hussar et al. 2012).

The biodegradation of PAHs in aqueous solutions has recently gained increased interest because it provides an inexpensive choice for PAH treatment and innocuous end products. Different microbial species isolated from various contaminated sites can utilize PAHs as a sole source of carbon and energy and converted them to harmless end products (Kristanti et al. 2018; Wang et al. 2018; Lee et al. 2019). Although pure strains can readily biodegrade PAHs, the biodegradation treatment can be improved if a mixed bacterial culture can be used. The multiple metabolic properties of the mixed culture of microorganisms can increase the biodegradation treatment efficiency, since the metabolic intermediate products of one species can be utilized by other species (Moscoso, et al. 2012; Fulekar 2017). Monteiro et al. (2000) reported that the use of mixed cultures provides a wider spectrum of metabolic capacity, which is recommended to prevent the production of toxic intermediate products during biological degradation.

Sewage sludge was selected as an inexpensive source of mixed culture of microorganisms; it contains many bacterial species, viruses, fungi, yeast, and protozoa (Ishak et al. 2011). In addition, sewage sludge is generally rich in nitrogen, which is necessary for the growth of microorganisms. Therefore, microorganisms grown in such waste can be used for the treatment of many types of contaminants. Furthermore, sewage waste sludge can be found in large quantities in wastewater treatment plants which need to be reduced, therefore utilizing the sewage waste sludge in biodegradation treatment has a significant interest (Maeda et al. 2005; Mustafa et al. 2015). The sewage sludge in the present study was collected from the sludge drying beds in the Al-Rustamiyah sewage treatment plant, Baghdad, Iraq. The plant contained 14 drying beds, each with a dimension of $300 \times 25 \times 1 \mathrm{~m}^{3}$, and the production of each drying bed is about $7500 \mathrm{~m}^{3}$ of waste sludge within 20 days. 
The bioavailability of PAHs is related to the existence of these compounds in a media to be readily taken up by the microorganisms and subsequently biodegraded. Because of the low solubilities of PAHs in aqueous solution, the biodegradation rate is limited by the dissolution rate of these pollutants into the aqueous phase, where they can be bioavailable to the microorganisms. The dissolution rate of PAH particles can be increased by improving the hydrodynamic conditions inside the bioreactor (Riess et al. 2005; Wang et al. 2008; Nikakhtari et al. 2014). The roller bioreactor contained inert beads offer an advantage in which the turbulence created by the rotation of the reactor with the beads can increase the dissolution rate by reducing the film thickness between the solid phase of the particles and the liquid phase, which in turn increases the mass transfer rate. Also, the grinding force of the glass beads can reduce the size of naphthalene particles creating a large interfacial surface area for mass transfer.

Naphthalene is considered a volatile compound; therefore, there is a possibility of losing it from the aqueous solution during the biodegradation treatment. This loss may slow bacterial growth and gives erroneous results. In a roller bioreactor, the losses were minimized by using a sealed container in which mixing is achieved by a continuous rotation of the container on rollers, leaving the reactor closed and air supplies continuously or at specific intervals through a tube fitted into the cup of the reactor.

Due to the complex nature of the biodegradation process, it is difficult to modeled and simulated these processes by traditional mathematical models. Artificial neural networks (ANNs) are a promising and powerful modeling technique since the mathematical details of the phenomena related to the process are not required (Annadurai and Lee 2007; Khataee and Kasiri 2011; Olawoyin 2016).

In the present work biodegradation of naphthalene in an aqueous solution was carried out by using a roller bioreactor containing inert glass beads. Mix culture of microorganisms was isolated from sewage waste sludge, which exists in abundance, and adopted to biodegraded naphthalene. The dissolution rate of naphthalene particles in the aqueous phase was studied at different conditions in the roller reactor: size, loading of the inert glass beads, the rotation speed of the reactor, and the concentration of naphthalene. The optimum conditions were used to operate the roller bioreactor. An artificial neural network (ANN) model was used to predict the dissolution and biodegradation of naphthalene in a roller reactor. Using trained ANN results new input conditions for dissolution and biodegradation were predicted.

\section{Artificial neural network (ANN)}

The modeling of biodegradation processes is not simple, the microbial consortium consists of a variety of microorganisms, and the behavior of these microorganisms can be affected by many variables, which are usually nonlinear interactions; for that, the phenomenological modeling is difficult to apply. Thus, a powerful modeling technique is required to describe the nonlinearity of these processes (Khataee and Kasiri 
2011). Artificial neural networks are computational tools that can learn the behavior of a process and the relationship between the variables without any mathematical description and formulation of the phenomena related to the process (Hamzaoui et al. 2011; Dudhagara et al. 2016; Alalayah 2017).

An artificial neural network (ANN) is an assembly of simple processing elements known as neurons or nodes, analogous to the neurons in the brain (Elmolla and Chaudhuri 2011). Weights connect these neurons represent the strength of these interconnections. The neurons are arranged in the network structure by layers, input layer, hidden layer, and output layer. The number of neurons in the input layer is fixed by the number of input variables, whereas the number of neurons in the output layer equals the number of output variables. The critical aspect is to choose the number of neurons in the hidden layers and consequently the number of connection weights. A network with one hidden layer and a sufficiently large number of neurons can interpret any input-output structure (Pareek et al. 2002; Darioush et al. 2009).

The artificial neural network topology is determined by the number of layers, the number of nodes in each layer, and the nature of transfer functions. The optimization of ANN topology is considered an essential step in developing the model (Annadurai and Lee 2007). The optimum number of nodes in the hidden layer was estimated by setting a series of topologies. The number of hidden neurons was increased until minimum square error (MSE) was obtained. MSE measures the performance of the network according to Eq.1:

$$
M S E=\left(\frac{1}{n} \sum_{i=1}^{n}\left(y_{i p}-y_{i e}\right)^{2}\right)
$$

Where $n$ is the number of data points, $y_{i p}$ is the predicted value, $y_{i e}$ is the actual value, and $i$ is the index.

In a multi-layered feed-forward neural network, all the neurons of a particular layer are connected to all the neurons in the next layer in one direction. Each neuron input, $V_{i}$, is multiplied by the corresponding weight factor, $W_{i}$, The weighted sum of all input variables $k$ is transferred to the hidden neurons, an internal bias, $b$ was added to improve the network performance. The outcome is passed through a nonlinear activation transfer function $f$ to obtain the output of the hidden neuron $a$ as in Eq. 2:

$a=f\left(\sum_{i=1}^{k} W_{i} V_{i}+b\right)$

Figure1 represents the basics of an artificial neuron. The output of the hidden neuron then acts as inputs to the neuron in the output layer, where it is subjected to another transformation.

In the present work tangent sigmoid transfer function (tansig)was used as transfer functions in the hidden layer, which is given in Eq. 3:

$f(x)=\frac{2}{\left(1+e^{-2 x}\right)}-1$

The tangent sigmoid transfer function takes the input, which can have any value between plus and minus infinity, and settling the output into the range -1 to 1 . Sigmoid functions introduce nonlinearity into the model, which significantly increases the computational power of these modeling networks (Arranz et al. 
2008). The linear transfer function (purlein) was used in the output layer. The linear transfer function is quite simple; it directly transfers its input to its output (Khataee and Kasiri 2011; Perpetuo et al. 2012), as shown in Eq. 4:

$f(x)=x$

When training multilayer networks, the data was divided into three subsets. The first subset is the training set, which is used for updating the network weights and biases. The second subset is the validation set. The MSE of the validation set is monitored during the training process. The validation error decreases typically during the earlier phase of training, as does the training set error. When the network begins to overfit the data, the error on the validation set typically begins to rise. The network weights and biases are set at the minimum MSR of the validation set (Beale et al. 2011). The third subset is the test set; the trained ANN is used to simulate test data output. If the ANN gains values for the test data output within an acceptable limit, then the ANN was successfully trained and used as a predictive tool.

ANNs are trained using different algorithms. In the present study, Levenberg-Marquardt Backpropagation was used. It is the most widely used supervised learning algorithm for artificial neural networks (Alalayah 2017).

If considering network with $k$ input variables, one hidden layer with $s$ neurons, output layer with $l$ neurons, the transfer function is tansig in the hidden layer and purelin in the output layer, the network output can be expressed as (Hamzaoui et al. 2011):

out $_{l}=\sum_{s=1}^{S}\left[W o_{(l, s)}\left(\frac{2}{1+\exp \left(-2\left(\sum_{k=1}^{k}\left(W i_{(s, k)} * V_{k}\right)+b 1_{(s)}\right)\right)}-1\right)\right]+b 2_{l}$

where $W i$ and $W o$ are the weights of the input and output layer, $b 1$ and $b 2$ are the bias of the input and output layer, respectively.

The relative importance of the input variables in the ANN model can be determined depending on the connection weights. The calculations were made using Garson Equation (Garson 1991) as in Eq. 6:

$$
I j=\frac{\sum_{m=1}^{m=N h}\left(\left(\frac{\left|w_{i m}^{i h}\right|}{\sum_{k=1}^{N i}\left|w_{k m}^{i h}\right|}\right) \times\left|w_{m n}^{h o}\right|\right)}{\sum_{k=1}^{k=N i}\left\{\sum_{m=1}^{m=N h}\left(\frac{\left|w_{k m}^{i h}\right|}{\sum_{k=1}^{N i}\left|w_{k m}^{i h}\right|}\right) \times\left|w_{m n}^{h o}\right|\right\}}
$$

where $I j$ is the relative importance of the jth input on the output variable: $N i$ and $N h$ are the numbers of input and hidden neurons, respectively; $w$ is the connection weights; the superscripts $i, h$, and $o$ related to input, hidden, and output layers, respectively; and subscripts $k, m$, and $n$ related to input, hidden, and output neurons, respectively. 


\section{Materials and Methods}

\subsection{Materials}

Naphthalene is used in the present study; it is of analytical grade and purchase from Central Drug House $(\mathrm{CDH})$ India. The mineral nutrient medium applies to support microbial growth was McKinney's modified medium (Hill and Robinson 1975). The amount of the minerals in mg per liter of distilled water was: $\mathrm{KH}_{2} \mathrm{PO}_{4}, 420 ; \mathrm{K}_{2} \mathrm{HPO}_{4}, 375 ;\left(\mathrm{NH}_{4}\right)_{2} \mathrm{SO}_{4}, 237 ; \mathrm{NaCl}, 30 ; \mathrm{CaCl}_{2}, 30 ; \mathrm{MgSO}_{4}, 30 ; \mathrm{Fe}\left(\mathrm{NH}_{4}\right)_{2} \mathrm{SO}_{4}, 10$ and $1 \mathrm{~mL}$ of trace elements solution. The amount of trace element in mg per liter of distilled water was: $\mathrm{H}_{3} \mathrm{BO}_{3}, 300$; $\mathrm{CoCl}_{3}, 200 ; \mathrm{ZnSO}_{4} .7 \mathrm{H}_{2} \mathrm{O}, 100 ; \mathrm{MnCl}_{2}, 30 ; \mathrm{Na}_{2} \mathrm{MoO}_{4}, 30 ; \mathrm{NiCl}_{2}, 20 ; \mathrm{CuCl}_{2}, 10$. The $\mathrm{pH}$ of the final nutrient media is equal to 6.5-6.7. The nutrient broth was used in the isolation and adoption of microbial mix culture, it was purchased from HIMEDIA India. It contained yeast extract $1.5 \mathrm{~g} / \mathrm{L}$, beef extract $1.5 \mathrm{~g} / \mathrm{L}$, sodium chloride $5 \mathrm{~g} / \mathrm{L}$, and animal tissues $5 \mathrm{~g} / \mathrm{L}$, the $\mathrm{pH}=7.4$ at $25^{\circ} \mathrm{C}$.

The physical, chemical and, biological properties of the sewage waste sludge were listed in Table 1 .

\subsection{Isolation and Adaption of the Mixed Microbial Culture}

The mixed culture of microorganisms was isolated from the sewage waste sludge by taking a sample of $10 \mathrm{~mL}$ of the sewage, mixed with $250 \mathrm{~mL}$ of the nutrient broth, and placed in a rotary shaker, $150 \mathrm{rpm}$ at $37^{\circ} \mathrm{C}$ for one week. After that, $10 \mathrm{~mL}$ of the shaken solution was mixed with another $250 \mathrm{~mL}$ of nutrient broth and shaken for one week at $37^{\circ} \mathrm{C}$. This procedure was repeated four times to ensure that proper isolation of the mixed microbial culture was reached.

To adopt the mixed culture to naphthalene, $10 \mathrm{~mL}$ of isolated culture was mixed with $250 \mathrm{~mL}$ of nutrient broth. Then $2 \mathrm{~g}$ of glucose (as a simple carbon source compound) and $0.1 \mathrm{~g}$ of naphthalene were added. The solution was subsequently placed in the shaker for one week at $37^{\circ} \mathrm{C}$. This procedure was repeated by gradually decrease the glucose and increase the naphthalene concentrations. Eight weeks was required to obtain a proper adoption of the mixed culture on naphthalene.

\subsection{Apparatus and experimental procedures}

The roller reactor used in the present study was locally constructed. It consists of $5 \mathrm{~L}$ glass bottles $(15 \mathrm{~cm}$ inside diameter and $30 \mathrm{~cm}$ length); one bottle was fitted with four stainless steel baffles, held equidistant around the inside circumference, and measuring $1.5 \mathrm{~cm}$ in width and $16 \mathrm{~cm}$ in length. The glass bottle is rotated on two roller bars by a heavy-duty motor. A pulley is mounted at one side of each roller bar and connected with a belt to provide a simultaneous rotation once the motor starts, as shown in Fig.2. The roller reactor was supplied with a variable speed regulator $(0-100 \mathrm{rpm})$. The reactor was operated with $1 \mathrm{~L}$ of working volume (volume of beads plus aqueous phase) at room temperature (about $25^{\circ} \mathrm{C}$ ). The glass bottle was supplied with a Teflon cap with two openings, one opening fitted with stainless steel tube, allowing continuous air injection to the bioreactor, and the second opening was used as a vent opening. Airflow at a 
rate of $3.5 \mathrm{~L} / \mathrm{min}$ was supplied to the bioreactor by an air pump (Rs-610 Zhongshan Risheng Electrical Products Co., China). Borosilicate glass beads of 3.0, 5.0, and $6 \mathrm{~mm}$ diameter were used in the present work.

In dissolution experiments, the effects of glass beads load\% ((volume of glass beads/total working volume) *100), glass beads size, the rotation speed of the roller reactor, naphthalene concentration, and the type of roller reactor, on the extent of mass transfer were studied. The conditions for the experiments are summarized in Table 2. Different loading was obtained by adding the proper quantity and size of glass beads to a distilled water in the glass bottle, keeping the total working volume (the volume of the distilled water plus the glass beads) constant at 1L. Naphthalene particles are then added to the glass bottle based on the volume of the aqueous phase to give the designated concentration. The roller reactor was operated at a required rotation speed, and the concentration of dissolved naphthalene was monitored at a regular period until it reached saturation level.

In biodegradation experiments, the roller bioreactor was implemented at naphthalene concentrations of 300 and $500 \mathrm{mg} / \mathrm{L}$, for the conditions of $40 \%$ load, $6 \mathrm{~mm}$ size and $50 \%$ load, $5 \mathrm{~mm}$ size at $50 \mathrm{rpm}$ corresponding to the optimum conditions for the mass transfer of naphthalene particles as determined in the dissolution experiments.

The nutrient medium and the glass beads were added to the glass bottle of the bioreactor, sterilized at $121{ }^{\circ} \mathrm{C}$; after it cools, the required amount of naphthalene was added. The content of the bioreactor was then inoculated with $2.5 \%$ of acclimatized mixed culture. In all biodegradation experiments, the working volume was kept constant at 1L. The Teflon cap was fixed at the glass bottle mouth of the bioreactor, and the air was allowed to pass through the stainless-steel tube to supply oxygen for the biodegradation process. The bottle was placed horizontally on the roller bioreactor and allowed to rotate at the required speed. Samples were taken at regular intervals for analysis by stopping the rotation of the bottle and taking the sample, then the rotation was resumed.

The control experiments were performed for both concentrations of naphthalene 300 and $500 \mathrm{mg} / \mathrm{L}$ in the absence of glass beads. The volume of the aqueous phase was kept at $0.5 \mathrm{~L}$ to simulate the aqueous phase in the presence of glass beads.

To assess the reproducibility of the experimental data, the experiments were carried out in duplicates, and the values shown in the figures relate to mean values.

\subsection{Naphthalene Concentration Measurements}

To determine the dissolved naphthalene concentrations during the dissolution experiments, the rotation of the roller was stopped, the reactor was allowed to settle for 15 seconds then $5 \mathrm{~mL}$ samples were taken from the bottom of the aqueous phase using a stainless-steel needle then the liquid was filtered through $0.22 \mu \mathrm{m}$ nylon filter to remove undissolved particles, the filtrate was transferred to a cuvette to measure the 
absorbance. The absorbance was measured by using a UV-vis spectrophotometer (Model T80 from PG Instrument Ltd, England) at $275 \mathrm{~nm}$. A calibration curve was developed previously to identify the relationship between the absorbance and concentration of dissolve naphthalene.

The naphthalene concentration during biodegradation experiments was determined by taking $5 \mathrm{~mL}$ of a well-shaken sample every day, to which $10 \mathrm{~mL}$ of ethanol was added to dissolve naphthalene particles and suppress bacteria. The sample was shaken for one minute in a vortex mixer, then centrifuged to separate the biomass and filtered in a $0.22 \mu \mathrm{m}$ nylon filter to eliminate any particles, including biomass. The sample was then injected into High-Performance Liquid Chromatography (HPLC, PerkinElmer series 200, USA). The stationary phase is $\mathrm{C} 18$ column $(25 \mathrm{~cm} \times 4.6 \mathrm{~mm}, 5 \mu \mathrm{m}$ particle size $)$ Discovery, from Supelco. The mobile phase consists of a mixture of acetonitrile and water (65:35). Peaks were detected with UV-vis spectrophotometer at $275 \mathrm{~nm}$. The HPLC reading was multiplied by 3 to obtain naphthalene concentration before dilution.

\subsection{Biomass Concentration Measurements}

To measure the biomass concentration a well-shaken sample of $5 \mathrm{~mL}$ was taken from the bioreactor. The sample was filtered through coarse paper (Whatman Grade 41) into a cuvette to exclude the effect of bubbles and naphthalene particles on the optical density (OD) values. The OD of the microbial culture was measured at $600 \mathrm{~nm}$ using a UV-Vis spectrophotometer (Model T80 from PG Instrument Ltd, England).

The obtained OD values were converted to grams of cell dry weight per liter using an experimental calibration curve (Biomass concentration $(\mathrm{g} / \mathrm{L})=0.9 \times \mathrm{OD})$, follow the procedure described by $\mathrm{Yu}(2006)$.

\section{Results and Discussion}

\subsection{Naphthalene Dissolution}

The microorganisms can only utilize PAH particles in the dissolved state; therefore, enhancing the dissolution from the solid phase to the aqueous phase is an essential step for biodegradation treatment. Different variables were tested in the present work to improve the extent of mass transfer rate and, in turn, the biodegradation rate in roller reactor. These variables include glass beads load (volume of glass beads/total working volume), glass beads size, the rotation speed of the roller reactor (rpm). Also, different concentrations of naphthalene particles were tested.

The effect of glass bead loading and size on the dissolution rate in the roller reactor was tested at an initial concentration of naphthalene $300 \mathrm{mg} / \mathrm{L}$ and $50 \mathrm{rpm}$ as shown in Fig 3. Different loading (0-50\%) and size of glass beads 3,5 , and $6 \mathrm{~mm}$ were used.

It can be seen from Fig. 3 for all sizes of glass bead $(3,5$, and $6 \mathrm{~mm})$ the addition of glass beads enhanced the dissolution rate of naphthalene. Faster rates were noticed when the loading of glass beads was increased from $0 \%$ to $50 \%$. Further increase in glass beads loading is not desired because the liquid volume available 
for biodegradation would be small. Increased mixing and turbulence in the roller reactor due to glass beads addition forced naphthalene molecules to move through the solid-liquid resistance film and increased the mass transfer rate.

Naphthalene dissolution in roller reactor operating with baffles only was shown in Fig. 3A. The dissolution rate of naphthalene in roller reactor with baffles was faster than in the roller reactor with no glass beads (0\% load) but not faster than the rate in roller reactor with glass beads.

In a batch system, the mass transfer from the surface of a particle through the liquid film around the particle can be explained by Eq. 7 (Mulder et al. 1998; Purwaningsih et al. 2002):

$\frac{d C_{l}}{d t}=\frac{A}{V} k_{l}\left(C_{l}^{*}-C_{l}\right)$

where:

$V:$ aqueous phase volume $\left(\mathrm{m}^{3}\right)$

$A:$ the total interfacial area between solid and liquid $\left(\mathrm{m}^{2}\right)$

$k_{l}:$ film mass transfer coefficient $(\mathrm{m} / \mathrm{hr})$

$C_{l}$ : concentration of naphthalene in the bulk liquid $(\mathrm{mg} / \mathrm{L})$

$C_{l}^{*}$ : saturated concentration of naphthalene in the liquid film adjacent to solid (mg /L)

$t:$ time (hr)

Because it is difficult to determine accurately the total surface area of particles available for mass transfer, a combined form of mass transfer coefficient is used, as in Eq. 8:

$$
\frac{A}{V} k_{l}=k_{l} a
$$

where $k_{l} a\left(\mathrm{hr}^{-1}\right)$ referred to a volumetric mass transfer coefficient.

Then Eq.8 can be written as:

$\frac{d C_{l}}{d t}=k_{l} a\left(C_{l}^{*}-C_{l}\right)$

integrating Eq. 9 with respect to time assuming a constant surface area of the particles and $C_{l}=0$ at $t=0$ gives:

$\ln \left(\frac{C_{l}^{*}-C_{l}}{C_{l}^{*}}\right)=-k_{l} a t$

$k_{l} a$ represent the slope of the line observed from the initial part of the dissolution curve when the function $\ln \left(\frac{C_{l}^{*}-C_{l}}{C_{l}^{*}}\right)$ plotted against $t$.

The value of volumetric mass transfer coefficient $k_{l} a$ represent the factor controlling the rate of particle dissolution.

Figure 4 shows the values of the volumetric mass transfer coefficient $k_{l} a$ at different loadings of glass beads at $5 \mathrm{~mm}$ size. $k_{l} a=50.425 \mathrm{hr}^{-1}$ for $50 \%$ loading while $k_{l} a=4.612 \mathrm{hr}^{-1}$ only for no glass beads roller reactor ( $0 \%$ loading) and $5.579 \mathrm{hr}^{-1}$ for baffle roller reactor. 
Figure 5 illustrate the relation between $k_{l} a$ and the glass beads loading for three different sizes 3,5 , and $6 \mathrm{~mm}$ of glass beads. It can be noticed that as the loading and the size of glass beads increases, the volumetric mass transfer coefficient increases too.

Figure 6 shows the dissolution rate of naphthalene for different roller speed rotations 30, 50, and70 rpm at a different load of glass beads 30,40 , and $50 \%$. The size of glass beads is equal to $6 \mathrm{~mm}$, and naphthalene concentration $300 \mathrm{mg} / \mathrm{L}$. Figure 7 illustrates the dependency of the volumetric mass transfer coefficient on roller speed rotation. The best result was obtained at 50rpm and 50\% load $\left(k_{l} a=60.36 \mathrm{hr}^{-1}\right)$.

The effect of initial naphthalene concentration $300,500,1000$, and $3000 \mathrm{mg} / \mathrm{L}$ on the dissolution rate was shown in Fig. 8A, at glass bead size 6mm, 40\% load, and 50rpm. The dependency of the volumetric mass transfer coefficient on naphthalene concentration was illustrated in Fig. 8B. $k_{l} a$ was increased when the initial concentration of naphthalene increased from 300 to $500 \mathrm{mg} / \mathrm{L}$ then it slows down for 1000 and $3000 \mathrm{mg} / \mathrm{L}$. $k_{l} a$ equal to $48.33,59.166,65.226$, and $67.314 \mathrm{hr}^{-1}$ for $300,500,1000$ and 3000mg/L, respectively. A higher initial concentration of naphthalene will increase the driving force for mass transfer and increase the specific solid surface area for mass transfer to the liquid phase (Riess et al. 2005: Lin et al. 2010).

Yu et al. (2006) used a bead mill roller reactor to improve the mass transfer of the substrate from the solid phase to the liquid phase. They reported that $k_{l} a$ equal to $23 \mathrm{hr}^{-1}$ for a reactor with $50 \%$ load and $5 \mathrm{~mm}$ size of beads, 50rpm, and $1000 \mathrm{mg} / \mathrm{L}$ naphthalene concentration. Compared with the present work $k_{l} a$ equal to $67.314 \mathrm{hr}^{-1}$ for $40 \%$ load, 6mm size, 50rpm and, 1000mg/L naphthalene, it represents 2.9 times higher.

\subsection{Biodegradation}

The capability of the acclimatized mix culture of microorganisms from sewage waste sludge to biodegraded naphthalene using glass beads roller bioreactor was implemented in the present work. Depending on the previous experimental results for naphthalene dissolution, different biodegradation treatments were carried out. The first treatment was carried out at $5 \mathrm{~mm}$ size of glass beads, $50 \%$ load, and 50rpm, and in the second, the treatment was carried out at $6 \mathrm{~mm}$ size of glass beads, $40 \%$ load, and 50rpm. The naphthalene concentration was tested for 300 , and $500 \mathrm{mg} / \mathrm{L}$ for the previously mentioned biodegradation experiments. Biodegradation experiments with no glass beads were accomplished at $0.5 \mathrm{~L}$ of the aqueous phase to simulate the working volume in the glass beads bioreactor as mentioned in section 2.3.

Figure 9 demonstrates the depletion curves of $300 \mathrm{mg} / \mathrm{L}$ naphthalene in roller bioreactors and the growth curves of mixed culture. As shown in Fig. 9, the biodegradation of naphthalene in the roller bioreactor with no glass beads proceeded at a slow rate until depletion after seven days of incubation time. In the presence of glass beads, the biodegradation rate was faster; it depleted after four days of incubation. There was no noticeable difference in the biodegradation rate for the treatments with glass beads bioreactors. As noticed previously from naphthalene dissolution experiments, the volumetric mass transfer coefficient was 50.424 
$\mathrm{hr}^{-1}$ and $48.33 \mathrm{hr}^{-1}$ for $50 \%$ load with $5 \mathrm{~mm}$ size and for $40 \%$ load with $6 \mathrm{~mm}$ size, respectively, which represent close values of volumetric mass transfer coefficients. This may confirm that the biodegradation results of the mentioned treatments with glass beads have no noticeable difference. The decrease in naphthalene concentration with time until depletion indicated that the acclimatized mix culture from sewage waste sludge could utilize naphthalene as a sole source of carbon and energy.

The growth curve of the microorganisms, as shown in Fig. 9, indicate a one-day lag phase for no glass beads bioreactor, and the lag phase in glass bead bioreactors was insignificant that is due to a proper mixing that supplies sufficient substrate and air to the microorganisms.

The performance of batch bioreactor can be derived from the material balance for the substrate around the bioreactor as shown in the below equation:

$r_{s}=\frac{d s}{d t}$

where $t$ is time, $s$ is the substrate concentration in $\mathrm{mg} / \mathrm{L}$, and $r_{S}$ is the rate of substrate consumption (the biodegradation rate) in $\mathrm{mgL}^{-1} \mathrm{hr}^{-1}$. The maximum rates of naphthalene consumption represent the slope of naphthalene concentration decreasing line at the exponential growth phase.

The biodegradation rate of naphthalene was equal to $1.99 \mathrm{mgL}^{-1} \mathrm{hr}^{-1}$ for bioreactor with no beads. While it is equal to 5.42, and $5.54 \mathrm{mgL}^{-1} \mathrm{hr}^{-1}$ for bioreactor with $40 \%$ load, $6 \mathrm{~mm}$ size and $50 \%$ load, $5 \mathrm{~mm}$ size of glass beads, respectively with regression coefficient $\left(\mathrm{R}^{2}\right)$ more than 0.96 . The biodegradation rate for glass beads bioreactors was about 2.75 times faster than the roller bioreactor with no glass beads which confirms that the presence of glass beads enhances the mass transfer of the substrate from the solid phase to the aqueous phase to where the microorganism can utilize the naphthalene.

Biodegradation treatment is a slow process; therefore, increasing the biodegradation rate and decreasing the biodegradation time gives a vital interest for the treatment in glass beads roller bioreactor.

Figure 10 shows the depletion curves of $500 \mathrm{mg} / \mathrm{L}$ naphthalene and growth curves of the mixed culture of microorganisms. The time required for complete degradation of naphthalene is equal to 9days for the bioreactor with no glass beads and 5days for glass beads bioreactors. A longer time was needed for the microorganisms to degrade a higher concentration of naphthalene, as reported by many authors (Lin et al. 2010; Fulekar 2017). The biodegradation rate is equal to $2.33,7.29$, and $7.85 \mathrm{mg} / \mathrm{L}^{-1} \mathrm{hr}^{-1}$ for bioreactors with no glass beads, $40 \%$ load with $6 \mathrm{~mm}$, and $50 \%$ load with $5 \mathrm{~mm}$ glass beads, respectively, with $\mathrm{R}^{2}$ more than 0.95 . The biodegradation rate in the bioreactor with glass beads is about 3.25 times faster than in the reactor with no beads. The biodegradation rate increased as the concentration of naphthalene rose that is higher concentration provide a higher volumetric mass transfer coefficient as illustrated in Fig.8B. Also, a high biodegradation rate indicates that the mixed culture of microorganisms from sewage waste sludge could degrade high concentrations of naphthalene until depletion. 
Janbandhu and Fulekar (2011) reported that using a mixed culture of microorganisms which have a wider spectrum of metabolic properties will enhance the treatment since the metabolic intermediates produced by one organism may use as substrates for the growth of others.

Fulekar (2017) isolate a microbial consortium contained five microorganisms, Microbacterium sp., Sphingobacterium sp., Bacillus cereus, Bacillus licheniformis, and Achromobacter insolitus, from an old petrochemical waste disposal site located at Nagpur, India. The result shows that the consortium capable to degraded $98.4 \%$ of $500 \mathrm{mg} / \mathrm{L}$ naphthalene within ten days in the shake flask bioreactor.

Microbial cell growth in a batch reactor can be represented by Malthus law:

$\frac{d x}{d t}=\mu x$

where $x$ is the biomass concentration $(\mathrm{g} / \mathrm{L})$ at time $\mathrm{t}, \mu$ is the specific growth rate $\left(\mathrm{hr}^{-1}\right)$ and $t$ is the incubation time (hr). The specific growth rate was determined from the slope of $\ln \left(x / x_{o}\right)$ against time, during the exponential growth phase, $x_{o}$ represents the initial biomass concentration.

Referring to the growth curves in Fig. 9, the specific growth rate $\mu$ was determined to be $0.031,0.050$ and $0.054 \mathrm{hr}^{-1}$ for no glass beads, $40 \%$ load with $6 \mathrm{~mm}$ and $50 \%$ load with $5 \mathrm{~mm}$ glass beads at $300 \mathrm{mg} / \mathrm{L}$ of naphthalene concentration, respectively with $\mathrm{R}^{2}$ equal to 0.99 . The specific growth rate $\mu$ was increased in the bioreactor with glass beads. Referring to the growth curves in Fig. 10, $\mu$ was determined to be 0.043 , 0.061 , and $0.065 \mathrm{hr}^{-1}$ for no glass beads, $40 \%$ load with $6 \mathrm{~mm}$, and $50 \%$ load with $5 \mathrm{~mm}$ glass beads at $500 \mathrm{mg} / \mathrm{L}$ naphthalene concentration, respectively with $\mathrm{R}^{2}$ more than 0.95 . It can be observed that $\mu$ was increased in the bioreactor with glass beads. The specific growth rate $\mu$ increased as the concentration of naphthalene increased, indicating no inhibitory effect on the microbial growth at $500 \mathrm{mg} / \mathrm{L}$ concentration. Increasing the initial concentration of substrate can provide enough driving force to overcome the mass transfer resistances, which in turn increases the availability of these substances towards the microorganisms in the mixed culture. Thus, high initial concentration can improve the degradation process and enable the microorganisms in the mixed culture to survive and degrade high concentrations, as agreed by (Lin et al., 2010). Although the probability of producing toxic metabolic intermediates during biological treatment may be increased at a high concentration of substrate, using mixed culture with a wider spectrum of metabolic properties will improve the treatment (Janbandhu and Fulekar 2011).

\subsection{Artificial neural network}

Neural network Toolbox in MATLAB R2020a (Mathworks Inc., USA) was used to model and predict the dissolution and the biodegradation treatment of naphthalene in glass beads roller reactor.

The input data matrix for naphthalene dissolution (5x163) consists of five sets of input data: time (hr), initial concentration of naphthalene $(\mathrm{mg} / \mathrm{L})$, glass beads load \%, glass beads size $(\mathrm{mm})$, and the rotation speed of 
the roller reactor (rpm). The output data matrix $(1 \times 163)$ consists of one set of data represent the naphthalene concentration $(\mathrm{mg} / \mathrm{L})$. The data were divided randomly into training $(70 \%)$, validation $(15 \%)$, and testing (15\%), as a default option in the MATLAB toolbox, that is 115 samples for training, 24 samples for validation, and 24 samples for testing.

For biodegradation, the input data matrix $(4 \times 40)$ consists of four sets of input data: time (hr), initial concentration of naphthalene $(\mathrm{mg} / \mathrm{L})$, glass beads load $\%$ and, glass beads size $(\mathrm{mm})$. The output data matrix ( $2 \times 40)$ consists of two sets of data represent the naphthalene and the biomass concentration $(\mathrm{mg} / \mathrm{L})$. The data were divided randomly into training 28 samples, validation 6 samples, and testing 6 samples, as a default option in the MATLAB toolbox. ANN topology for dissolution and biodegradation were represented in Figs.11 and 12.

The neural architecture was set by using a three-layer feed-forward network with a hyperbolic tangent sigmoid transfer function (tansig) at the hidden layer and a linear transfer function (purelin) at the output layer. The network was trained by using the Levenberg-Marquardt backpropagation algorithm. The optimal number of neurons in the hidden layer was chosen to be 10 at minimum mean square error (MES).

Figure 13 illustrates the network training performance for dissolution data; it represents the MSE for training, validation, and testing data. Training automatically stops by increasing MSE of the validation samples; the beast validation performance was obtained at MSE equal to 0.00317. Figure 14 illustrates the network training regression for the dissolution data. The regression values for all datasets equal $99.2 \%$, indicating that the ANN model was able to model the naphthalene dissolution accurately and reproduce the experimental results with quite good precision. Figure 15 shows the actual and the predicted dissolution results for the roller reactor at naphthalene concentration of $500 \mathrm{mg} / \mathrm{L}, 40 \%$ load, $6 \mathrm{~mm}$ size, and 50rpm. The predicted values were quite close to the actual values, which confirms that the model is satisfactory.

From the trained ANN results, the dissolution of naphthalene in the roller reactor with 40rpm and for an initial concentration of $400 \mathrm{mg} / \mathrm{L}$ can be predicted; the results shown in Fig. 15 seem to be reasonable.

Figures 16 and 17 illustrate the network training performance and regression for the biodegradation data, respectively. The best validation performance was obtained at MSE equal to 0.00249, as shown in Fig.16. The regression values for all datasets equal 98.3\%, as shown in Fig.17, which indicates that the ANN model can model the naphthalene biodegradation with good precision. The predicted values show in Figs. 9 and 10 validate that these values are in good agreement with the experimental results.

Depending on trained ANN results, the predicted values of naphthalene and biomass concentration are displayed in Fig. 18 for roller bioreactor with no glass beads and with glass beads at 400mg/L concentration. The predicted values show a logical result.

The connection weights needed to determine the relative importance of the input variables for dissolution and biodegradation data were tabulated in Tables 3 and 4, respectively in which the weights between input 
and hidden layers represented by (w1) and the weights between hidden and output layers represented by (w2). Table 5 shows the relative importance of the input variables for the dissolution and biodegradation treatment. The incubation time reported the most influential parameter on the dissolution and biodegradation treatment; it represents $49 \%$ and $47 \%$ for dissolution and biodegradation treatment, respectively.

\section{Conclusions}

Sewage waste sludge can be found in large quantities in wastewater treatment plants which need to be reduced. In the present work mixed culture of microorganisms was isolated from the sewage waste sludge which is found in abundance in a waste treatment plant. The mixed culture was adopted to naphthalene which is considered one of the High Priority Pollutants and has limited solubility in water.

A roller bioreactor contained inert glass beads was used in the present work to increase the dissolution rate of naphthalene to be more available to the mixed culture of microorganisms. The effect of glass beads load, glass beads size, the rotation speed of the roller reactor, the type of the reactor, and the concentrations of naphthalene particles was tested to improve the dissolution rate. The results show that as the load and size of glass beads increase, the volumetric mass transfer coefficient increases too.

the volumetric mass transfer coefficient $k_{l} a$ equal to $50.424 \mathrm{hr}^{-1}$ and $48.33 \mathrm{hr}^{-1}$ for $50 \%$ load with $5 \mathrm{~mm}$ size and $40 \%$ load with $6 \mathrm{~mm}$ size, respectively, these two conditions represent the best conditions for the biodegradation treatment in roller bioreactor.

The biodegradation of $300 \mathrm{mg} / \mathrm{L}$ naphthalene in the roller bioreactor with no glass beads proceeded slowly until depletion after seven days of incubation time. In the presence of glass beads, the biodegradation rate was faster; it depleted after four days of incubation. The biodegradation rate of naphthalene was equal to $1.99 \mathrm{mgL}^{-1} \mathrm{hr}^{-1}$ for bioreactor with no beads, while it is equal to 5.42 , and $5.54 \mathrm{mgL}^{-1} \mathrm{hr}^{-1}$ for bioreactor with $40 \%$ load, $6 \mathrm{~mm}$ size and $50 \%$ load, $5 \mathrm{~mm}$ size of glass beads, respectively with regression coefficient $\left(\mathrm{R}^{2}\right)$ more than 0.96 . Thus, the biodegradation rate for glass beads bioreactors was about 2.75 times faster than the roller bioreactor with no glass beads.

For $500 \mathrm{mg} / \mathrm{L}$ naphthalene, the time required for complete degradation of naphthalene is equal to 9days for the bioreactor with no glass beads and 5days for glass beads bioreactors. The biodegradation rate is equal to $2.33,7.29$, and $7.85 \mathrm{mg} / \mathrm{L}^{-1} \mathrm{hr}^{-1}$ for bioreactors with no glass beads, $40 \%$ load with $6 \mathrm{~mm}$, and $50 \%$ load with $5 \mathrm{~mm}$ glass beads, respectively, with $\mathrm{R}^{2}$ more than 0.95 . The biodegradation rate in the bioreactor with glass beads is about 3.25 times faster than in the reactor with no beads.

The specific growth rate $\mu$ was increased in the bioreactor with glass beads it represents $0.031,0.050$, and $0.054 \mathrm{hr}^{-1}$ for no glass beads, $40 \%$ load with $6 \mathrm{~mm}$, and $50 \%$ load with $5 \mathrm{~mm}$ glass beads at $300 \mathrm{mg} / \mathrm{L}$ naphthalene concentration, respectively with $\mathrm{R}^{2}$ equal to 0.99 . For $500 \mathrm{mg} / \mathrm{L}$ concentration $\mu$ was 
determined to be $0.043,0.061$, and $0.065 \mathrm{hr}^{-1}$ respectively for the previously mentioned conditions with $\mathrm{R}^{2}$ more than 0.95 .

An artificial neural network (ANN) was used to model naphthalene dissolution and biodegradation. Three-layer feed-forward network with a hyperbolic tangent sigmoid transfer function (tansig) at the hidden layer and linear transfer function (purelin) at the output layer was used. The network was trained by using the Levenberg-Marquardt backpropagation algorithm. A correlation coefficient of $99.2 \%$ and $98.3 \%$ were obtained between the experimental and predicted output values for dissolution and biodegradation, respectively, indicating that the ANN model could efficiently predict the experimental results. The incubation time represents the most influential parameter on the dissolution and biodegradation treatment; it represents $49 \%$ and $47 \%$ for dissolution and biodegradation treatment, respectively.

Data Availability Statement All data that support the findings of this study are available from the corresponding author upon reasonable request.

Conflict of interest All the authors associated with this work declare that there is no conflict of interest.

Authors' Contributions All authors contributed to the study conception and design. Material preparation and data collection were performed by Sinan J. Mohammed and Yasmen A. Mustafa. Data analysis and validation were made by Sinan J. Mohammed, Yasmen A. Mustafa and Mohanad S. Jabbar. The first draft of the manuscript was written by Yasmen A. Mustafa and all authors commented on previous versions of the manuscript. All authors read and approved the final manuscrip.

Funding This study did not receive any funding support.

\section{References}

Alalayah, W. M. (2017). Simulation of the biodegradation of petroleum hydrocarbons utilizing Artificial Neural Networks, International Journal of Engineering Development and Research, 5(4), 891-896.

Annadurai, G., \& Lee, J. F. (2007). Application of artificial neural network model for the development of optimized complex medium for phenol degradation using Pseudomonas pictorum (NICM 2074). Biodegradation, 18(3), 383-392. https://doi.org/10.1007/s10532-006-9072-8

Arranz, A., Bordel, S., Villaverde, S., Zamarreño, J.M., Guieysse, B., \& Muñoz, R. (2008). Modeling photosynthetically oxygenated biodegradation processes using artificial neural networks. Journal of Hazardous Materials, 155(1-2), 51-57. DOI: 10.1016/j.jhazmat.2007.11.027.

ATSDR, 2005. Toxicology profile for polyaromatic hydrocarbons. ATSDR's Toxicological Profiles on CD-ROM, CRC Press, Boca Raton, FL. 
Beale M. H., Hagan M.T., Demuth H.B., Neural Network Toolbox ${ }^{\mathrm{TM}}$ User's Guide- User's Guide Version 7, 2011 by The MathWorks, Inc.

Bojes, K. H., \& Pope, G. P. (2007). Characterization of EPA's 16 priority pollutant polycyclic aromatic hydrocarbons (PAHs) in tank bottom solids and associated contaminated soils at oil exploration and production sites in Texas. Regulatory Toxicology and Pharmacology, 47, 288-295. https://doi.org/10.1016/j.yrtph.2006.11.007

Darioush, S., Aligoli, N., Alireza, K., \& Mahmoud, Z. (2009). Electrochemical treatment of dye solution containing C.I. Basic Yellow 2 by the peroxi-coagulation method and modeling of experimental results by artificial neural networks. Journal Electroanalytical Chemistry, 629,117-125.

https://doi.org/10.1016/j.jelechem.2009.02.002

Dudhagara, D.R., Rajpara, R.K., Bhatt, J.K., Gosai, H.B., \& Dave, B. (2016). Bioengineering for polycyclic aromatic hydrocarbon degradation by Mycobacterium litorale: Statistical and artificial neural network (ANN) approach. Chemometrics and Intelligent Laboratory Systems, 159, 155-163.

https://doi.org/10.1016/j.chemolab.2016.10.018.

Elmolla, E.S. \& Chaudhuri, M. (2011). The use of artificial neural Nnetwork (ANN) form modeling, simulation and prediction of advanced oxidation process performance in recalcitrant wastewater treatment, artificial neural networks - Application, Hui, C.L.P. (Ed.), ISBN: 978-953-307-188-6, InTech, DOI:10.5772/14920.

Fulekar, M. H., (2017). Microbial degradation of petrochemical waste-polycyclic aromatic hydrocarbons. Bioresources and Bioprocessing, 4 (1), 28. https://doi.org/10.1186/s40643-017-0158-4

Garson, G. D., (1991). Interpreting neural-network connection weights. AI Expert, 6, 47-51.

Hamzaoui,Y. EI., Hernández, J. A., Silva-Martínez, S., Bassam, A., Álvarez, A., \& Lizama-Bahena C.(2011). Optimal performance of COD removal during aqueous treatment of alazine and gesaprim commercial herbicides by direct and inverse neural network. Desalination, 277( 1-3), 325-337. https://doi.org/10.1016/j.desal.2011.04.060

Hill, G.A., \& Robinson, C. W., (1975). Substrate inhibition kinetics: phenol degradation by Pseudomonas putida. Biotechnology and Bioengineering, 17, 1599-1615. https://doi.org/10.1002/bit.260171105.

Hussar, E., Richards, S., Lin, Z. Q., Dixon, R. P., \& Johnson, K. A. (2012). Human health risk assessment of 16 priority polycyclic aromatic hydrocarbons in soils of chattanooga, Tennessee, USA. Water, air, and soil pollution, 223(9), 5535-5548. https://doi.org/10.1007/s11270-012-1265-7 
Ishak, W. W., Jamek, S., Jalanni, N. A., \& Jamaludin, N. F. M. (2011). Isolation and identification of bacteria from activated sludge and compost for municipal solid waste treatment system, International Conference on Environment Science and Biotechnology, Energy Procedia 00 (2011) 000-000

Janbandhu, A., \& Fulekar, M. (2011). Biodegradation of phenanthrene using adapted microbial consortium isolated from petrochemical contaminated environment. Journal of hazardous materials, 187, 333-340. doi: 10.1016/j.jhazmat.2011.01.034

Khataee, A.R. \& Kasiri, M.B. (2011), modeling of biological water and wastewater treatment processes using artificial neural networks. Clean Soil Air Water, 39: 742-749. https://doi.org/10.1002/clen.201000234

Kristanti, R. A., Hadibarata, T., Al Farraj, D. A., Elshikh, M. S., \& Alkufeidy, R., M. (2018). Biodegradation mechanism of phenanthrene by Halophilic Hortaea sp. B15. Water Air Soil Pollution, 229(10), 1-8. https://doi.org/10.1007/s11270-018-3969-9

Lee, Y., Lee, Y., \& Jeon, C. O. (2019). Biodegradation of naphthalene, BTEX, and aliphatic hydrocarbons by Paraburkholderia aromaticivorans BN5 isolated from petroleum-contaminated soil. Scientific Report, 9, 860. https://doi.org/10.1038/s41598-018-36165-x

Lin, C., Gan, L., \& Chen, Z. (2010). Biodegradation of naphthalene by strain Bacillus fusiformis (BFN). Journal of Hazardous Materials, 128, 771-777. https://doi.org/10.1016/j.jhazmat.2010.06.101

Maeda, M., Itoh, A., \& Kawase, Y. (2005). Kinetics for aerobic biological treatment of o-cresol containing wastewaters in a slurry bioreactor: biodegradation by utilizing waste activated sludge. Biochemical Engineering Journal, 22, 97-103. https://doi.org/10.1016/j.bej.2004.09.005

Monteiro, A. A. M. G., Boaventura, R. A, \& Rodrigues, A. E. (2000). Phenol biodegradation by Pseudomonas putida DSM 548 in a batch reactor. Biochemical Engineering Journal, 6, 45-49. https://doi.org/10.1016/S1369-703X(00)00072-3

Moscoso, F., Deive, F. J., Longo, M. A., \& Sanromán, M., A. (2012). Technoeconomic assessment of phenanthrene degradation by Pseudomonas stutzeri CECT 930 in a batch bioreactor. Bioresource Technology, 104, 81-89. https://doi.org/10.1016/j.biortech.2011.10.053

Mulder, H., Breure, A.M., Van Andel, J.G., Grotenhuis, J.T.C. \& Rulkens, W.H. (1998). Influence of hydrodynamic conditions on naphthalene dissolution and subsequent biodegradation. Biotechnology and Bioengineering, 57,145-154. https://doi.org/10.1002/(SICI)1097-0290(19980120)57:2<145::AIDBIT3>3.0.CO;2-N 
Mustafa, Y.A., Abdul-Hameed, H.M. and Razak, Z.A. (2015), biodegradation of 2,4dichlorophenoxyacetic acid contaminated soil in a roller slurry bioreactor. Clean Soil Air Water, 43, 1241-1247. https://doi.org/10.1002/clen.201400623

Nikakhtari, H., Song, W., Nemati, M. \& Hill, G. A. (2014). Oxygen mass transfer and scale-up studies in baffled roller bioreactors. Bioprocess and Biosystems Engineering, 37, 193-203. https://doi.org/10.1007/s00449-013-0985-4

Olawoyin R. (2016). Application of backpropagation artificial neural network prediction model for the PAH bioremediation of polluted soil. Chemosphere, 161, 145-150. https://doi.org/10.1016/j.chemosphere.2016.07.003

Pareek, V. K., Brungs, M. P., Adesina, A. A.,\& Raj Sharma,. (2002). Artificial neural network modeling of a multiphase photodegradation system. Journal of Photochemistry and Photobiology A: Chemistry, 149 (1-3), 139-146. https://doi.org/10.1016/S1010-6030(01)00640-2

Perpetuo, E. A., Silva, D. N., Avanzi, I. R., Gracioso, L. H., Baltazar, M. P., \& Nascimento, C. A. (2012). Phenol biodegradation by a microbial consortium: application of artificial neural network (ANN) modelling. Environmental technology, 33(13-15),1739-1745. https://doi.org/10.1080/09593330.2011.644585

Purwaningsih, I. S., Hill, G. A. \& Headley, J. V. (2002). Air Stripping and dissolution rates of aromatic hydrocarbon particles in a bioreactor. Chemical Engineering Communications, 189(2), 268-283. DOI:10.1080/00986440211842

Reddy, C. M., Eglinton, T. I., Hounshell, A., White, H. K., Xu, L., Gaines, R. B., \& Frysinger, G. S. (2002). The West Falmouth oil spill after thirty years: the persistence of petroleum hydrocarbons in mash sediments. Environmental Science \& Technology. 36, 4754-60. doi: 10.1021/es020656n

Riess, R., Nemati, M., Headley, J., \& Hill, G. (2005). Improved mass transfer and biodegradation rates of naphthalene particles using a novel bead mill bioreactor. Journal of Chemical Technology \& Biotechnology, 80(6), 662-668. https://doi.org/10.1002/jctb.1247

Yu, R., Nemati, M., Hill, G., \& Headley, J. (2006). Mass transfer and bioremediation of naphthalene and methyl naphthalenes in baffled and bead mill bioreactors. The Canadian Journal of Chemical Engineering, 84(3), 349-355. https://doi.org/10.1002/cjce.5450840311 
Wang, W., Wang, L., \& Shao, Z. (2018). Polycyclic aromatic hydrocarbon (PAH) degradation pathways of the obligate marine PAH degrader Cycloclasticus sp. strain P1. Applied and environmental microbiology, 84(21), e01261-18. https://doi.org/10.1128/AEM.01261-18

Wang, Y., Riess, R., Nemati, M., Hill, G., \& Headly, J. (2008). Scale-up impacts on mass transfer and bioremediation of suspended naphthalene particles in bead mill bioreactors. Bioresource Technology, 99:8143-8150. https://doi.org/10.1016/j.biortech.2008.03.070 
Table 1 Physical, chemical, and biological properties of sewage sludge

\begin{tabular}{lc}
\hline Physical characteristic (dry dead biomass) \\
Particle diameter & $0.775(\mathrm{~mm})$ \\
Surface area & $94.53\left(\mathrm{~m}^{2} / \mathrm{g}\right)$ \\
Actual density & $1741.6\left(\mathrm{~kg} / \mathrm{m}^{3}\right)$ \\
Bulk density & $609.9\left(\mathrm{~kg} / \mathrm{m}^{3}\right)$ \\
Particle porosity & 0.584 \\
T.S & $153950(\mathrm{mg} / \mathrm{l})$ \\
V.S & $78126(\mathrm{mg} / \mathrm{l})$ \\
Chemical characteristic $($ dry dead biomass) \\
pH & $5.5-6.3$ \\
CEC & $51.2 \mathrm{meq} / 100 \mathrm{~g}$ \\
Lead & $0.02 \mathrm{mg} / \mathrm{L}$ \\
Chromium & $0.01 \mathrm{mg} / \mathrm{L}$ \\
Cadmium & $0.02 \mathrm{mg} / \mathrm{L}$ \\
Biological characteristic $(\mathbf{l i v e ~ b i o m a s s )}$ \\
Bacteria & \\
Aeromonas species & $222000 \mathrm{CFU} / \mathrm{mL}$ \\
E. coli & $430000 \mathrm{CFU} / \mathrm{mL}$ \\
Pseudomonas species & $703500 \mathrm{CFU} / \mathrm{mL}$ \\
Klebsiella species & $210000 \mathrm{CFU} / \mathrm{mL}$ \\
Clostridium & $370000 \mathrm{CFU} / \mathrm{mL}$ \\
Staphylococcus species & $210000 \mathrm{CFU} / \mathrm{mL}$ \\
Streptococcus species & $490000 \mathrm{CFU} / \mathrm{mL}$ \\
Salmonella species & $190000 \mathrm{CFU} / \mathrm{mL}$ \\
Shiglladysente & $410000 \mathrm{CFU} / \mathrm{mL}$ \\
Fungi & \\
Penicillium species & $180000 \mathrm{CFU} / \mathrm{mL}$ \\
Yeast & \\
Candida albicans & $460000 \mathrm{CFU} / \mathrm{mL}$ \\
Protozoa & \\
Entamoeba species & $16000 \mathrm{CFU} / \mathrm{mL}$ \\
& \\
\hline
\end{tabular}


Table 2 The variables used in dissolution experiments and corresponding $k_{l} a$ values in each case

\begin{tabular}{llclll}
\hline $\begin{array}{c}\text { Type of roller } \\
\text { reactor }\end{array}$ & $\begin{array}{c}\text { Naphthalene } \\
\text { concentration } \\
(\mathrm{mg} / \mathrm{L})\end{array}$ & $\begin{array}{c}\text { Bead } \\
\text { Size } \\
(\mathrm{mm})\end{array}$ & Bead load \% & $\begin{array}{c}\text { Rotation } \\
\text { speed } \\
(\mathrm{rpm})\end{array}$ & $\begin{array}{c}\text { volumetric mass transfer } \\
\text { coefficient* } \\
k_{l} a\left(\mathrm{hr}^{-1}\right)\end{array}$ \\
\hline Control (no beads) & 300 & 5 & ------- & 50 & 4.6 \\
Baffle & 300 & 5 & ----- & 50 & 5.6 \\
Glass bead & 300 & 5 & $10,20,30,40,50$ & 50 & $8.5,10.5,14.8,20.4,50.4$ \\
Glass bead & 300 & 6 & $20,30,40,50$ & 50 & $28.2,35,48.3,60.4$ \\
Glass bead & 300 & 3 & $30,40,50$ & 50 & $9.3,13,22$ \\
Glass bead & 300 & 6 & 30 & $30,50,70$ & $23.7,35,45.5$ \\
Glass bead & 300 & 6 & 40 & $30,50,70$ & $29,48.3,52.7$ \\
Glass bead & 300 & 6 & 50 & $30,50,70$ & $38.8,60.4,63.7$ \\
Glass bead & $300,500,1000,3000$ & 6 & 40 & 50 & $48.3,59.2,65.2,67.3$ \\
\end{tabular}

* volumetric mass transfer coefficients in each row are presented in the same order as that of the variabies under investigation.

Table. 3 Weight connections for dissolution prediction: w1, the weights between input and hidden layers, and w2, the weights between hidden and output layers

\begin{tabular}{ccccccc}
\hline & \multicolumn{3}{c}{$\begin{array}{c}\text { W1 } \\
\text { Input }\end{array}$} & & W2 \\
Neuron & Time & $\begin{array}{c}\text { Initial } \\
\text { concentration }\end{array}$ & Load & Size & RPM & Concentration \\
\cline { 2 - 6 } & -0.8143 & -0.5370 & 0.6570 & 1.7315 & -0.0296 & -2.0243 \\
\hline 1 & 0.1270 & -0.0361 & 0.8638 & 1.0901 & 0.0926 & 1.2120 \\
2 & -2.3484 & -1.0118 & -1.2196 & -2.4140 & 1.6216 & 0.4234 \\
3 & 0.4807 & 3.1511 & -2.0411 & 2.0701 & -2.3781 & 3.8455 \\
4 & 4.5166 & 2.1189 & 1.8355 & -1.7240 & 0.6760 & 3.3462 \\
5 & -2.0324 & 3.0985 & 0.6792 & -3.3386 & 7.0441 & -0.0250 \\
6 & -24.8267 & 0.0145 & 0.3040 & 0.1488 & 0.0370 & -10.0891 \\
7 & 9.4658 & -5.1618 & -0.7182 & -0.2201 & -0.1878 & -0.7540 \\
8 & 5.8177 & 3.3548 & -1.5406 & 0.0529 & -0.7688 & -0.0727 \\
9 & -7.8660 & 4.5483 & -0.6777 & -0.6346 & -0.2866 & -0.7117 \\
10 & & & & & & \\
\hline
\end{tabular}


Table. 4 Weight connections for biodegradation prediction: w1, the weights between input and hidden layers and w2, the weights between hidden and output layers

\begin{tabular}{|c|c|c|c|c|c|c|}
\hline \multirow[b]{2}{*}{ Neuron } & \multicolumn{3}{|c|}{$\begin{array}{c}\text { W1 } \\
\text { Input }\end{array}$} & \multicolumn{3}{|c|}{$\begin{array}{c}\text { W2 } \\
\text { Output }\end{array}$} \\
\hline & Time & $\begin{array}{c}\text { Initial } \\
\text { concentration }\end{array}$ & Load & Size & C/Co & OD \\
\hline 1 & 1.168102 & 0.643625 & 2.104098 & -0.36529 & -0.09487 & -0.49106 \\
\hline 2 & -1.30443 & 1.669208 & -1.28611 & 0.246139 & -0.22468 & 0.517548 \\
\hline 3 & 0.358343 & -0.19011 & -1.11606 & -2.40036 & 0.03453 & 0.132087 \\
\hline 4 & -3.50555 & 0.191332 & -0.34338 & -0.55911 & 0.121618 & 2.183234 \\
\hline 5 & -1.53655 & 2.268408 & 0.993341 & -1.42558 & 0.060616 & -0.12505 \\
\hline 6 & -1.84273 & 0.291098 & -2.22997 & 1.657871 & 0.094288 & -0.10835 \\
\hline 7 & -4.07661 & -0.01559 & -0.59863 & -0.5099 & 0.113149 & -2.041 \\
\hline 8 & 1.071441 & 1.720864 & 1.299422 & 1.078938 & 0.006926 & 0.130987 \\
\hline 9 & -2.98414 & -1.15155 & 0.626928 & -0.14947 & -0.13126 & 0.047113 \\
\hline 10 & 2.830019 & -0.28929 & 0.010494 & -0.03189 & -1.22859 & 0.072315 \\
\hline
\end{tabular}

Table 5 Relative importance of input variables

\begin{tabular}{|l|cc|}
\hline \multirow{2}{*}{ Input variables } & \multicolumn{2}{|c|}{ Relative importance\% } \\
& Dissolution & Biodegradation \\
\hline Time & 49 & 47 \\
Concentration & 19 & 22 \\
Bead load & 12 & 10 \\
Bead size & 14 & 21 \\
rpm & 6 & --- \\
\hline
\end{tabular}




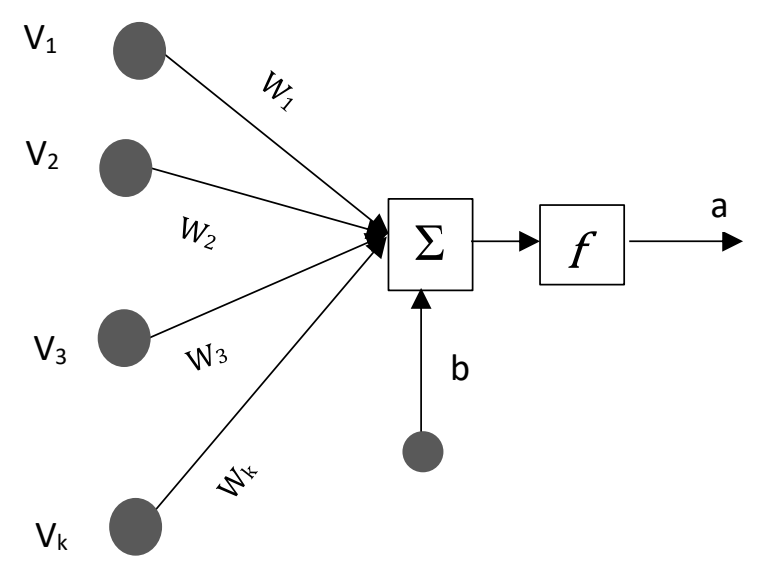

Fig.1 The basics of an artificial neuron

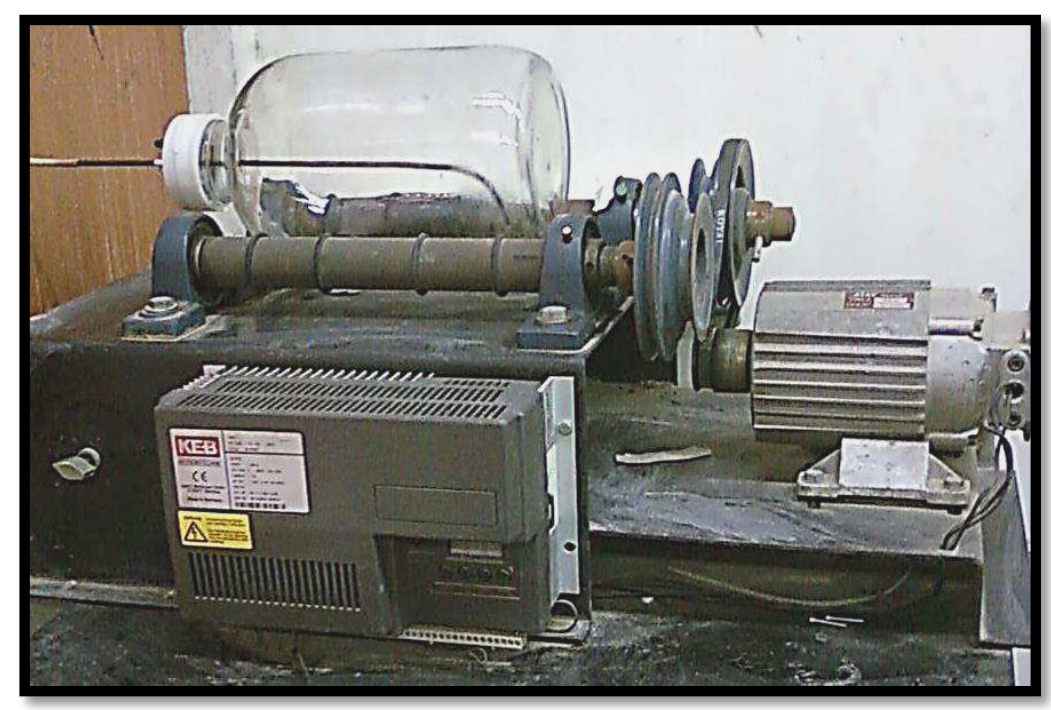

Fig.2 The roller reactor 

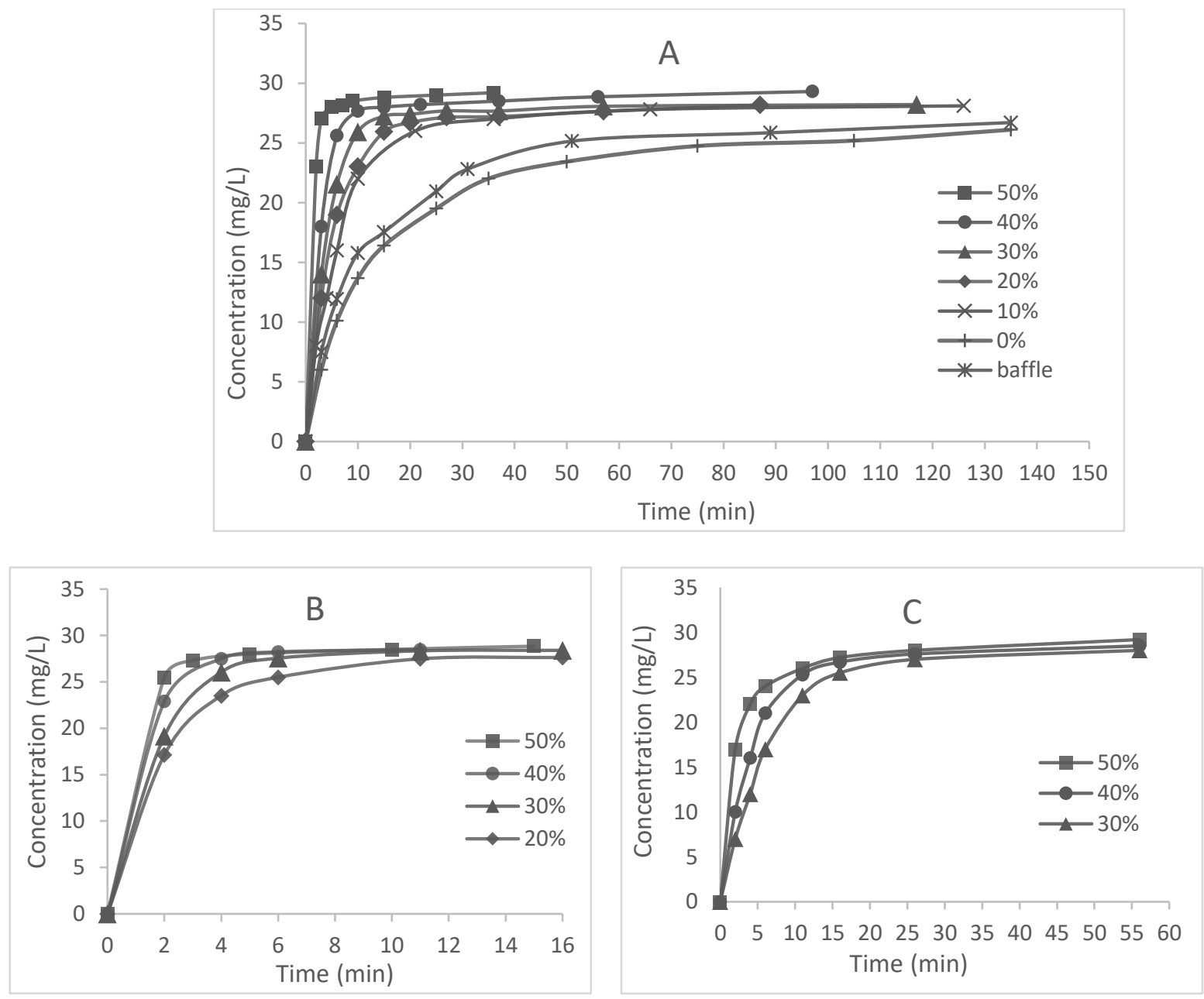

Fig. 3 Dissolution of naphthalene at different loadings and sizes of glass beads (A) $5 \mathrm{~mm}$ size, (B) $6 \mathrm{~mm}$ size, and (C) $3 \mathrm{~mm}$ size. Naphthalene concentration $300 \mathrm{mg} / \mathrm{L}$ and roller speed rotation 50rpm 


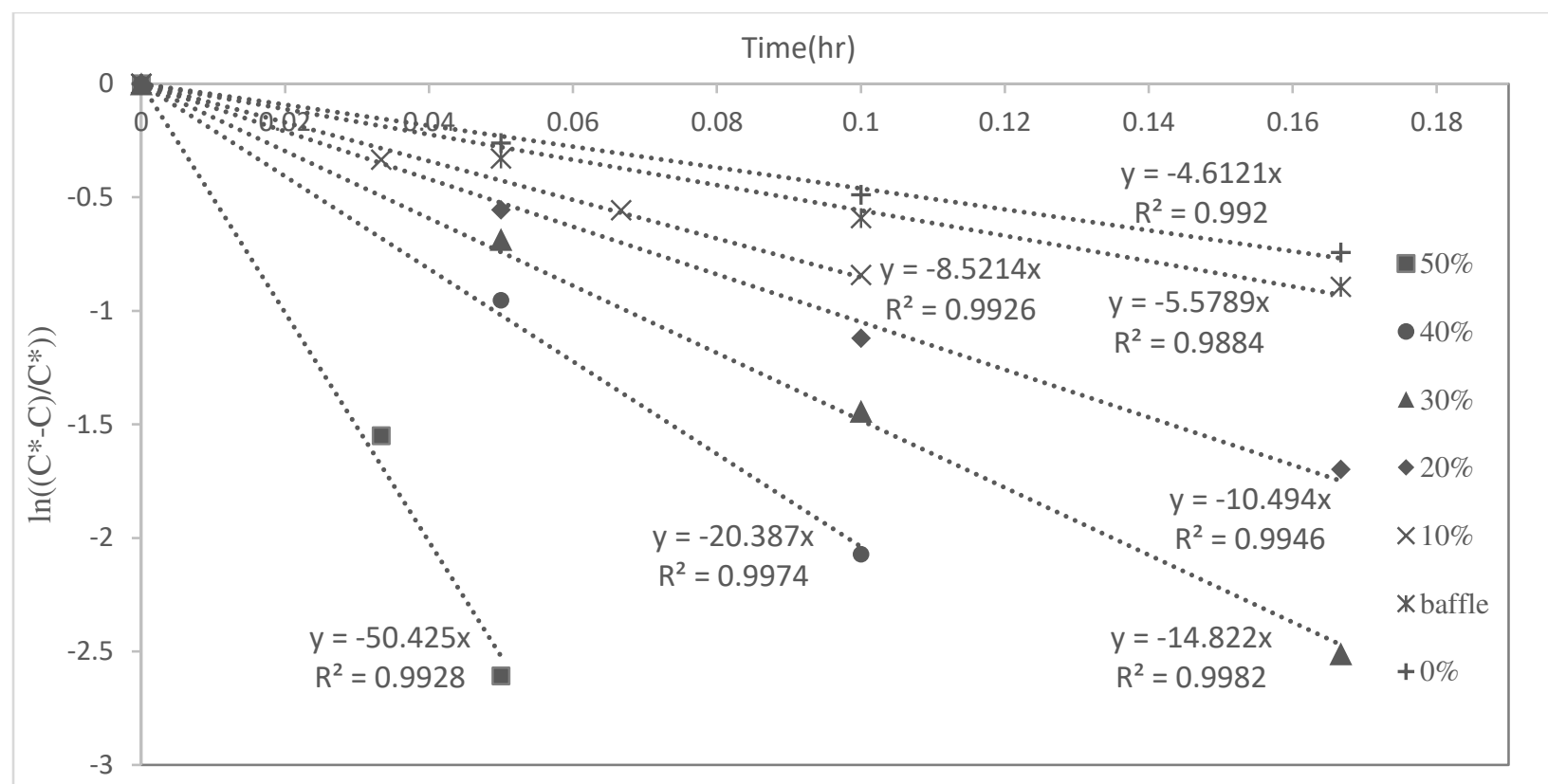

Fig. 4 Plott of the function $\ln \left(\frac{C_{l}^{*}-C_{l}}{C_{l}^{*}}\right)$ against the time $t$ to estimate the volumetric mass transfer coefficient $k_{l} a$ for glass bead size $5 \mathrm{~mm}$ at different loadings, naphthalene concentration $300 \mathrm{mg} / \mathrm{L}$

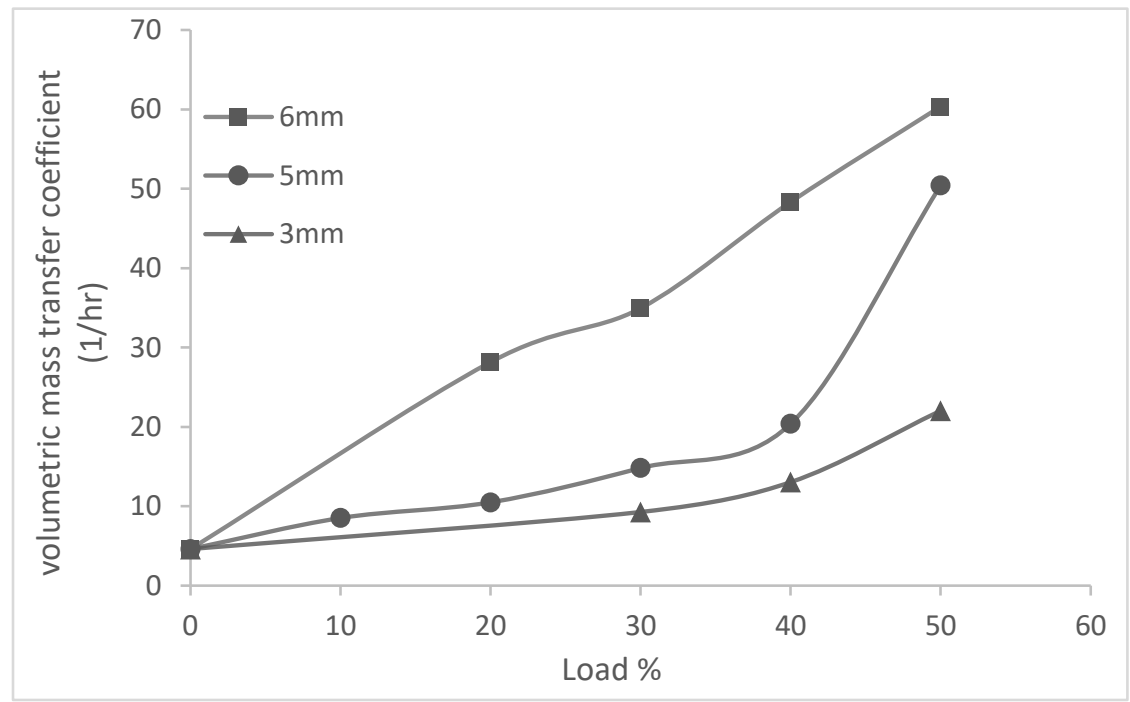

Fig. 5 Dependency of volumetric mass transfer coefficient on the loading of glass beads at 3,5, and 6mm size. Naphthalene concentration $300 \mathrm{mg} / \mathrm{L}$ and roller speed rotation $50 \mathrm{rpm}$ 

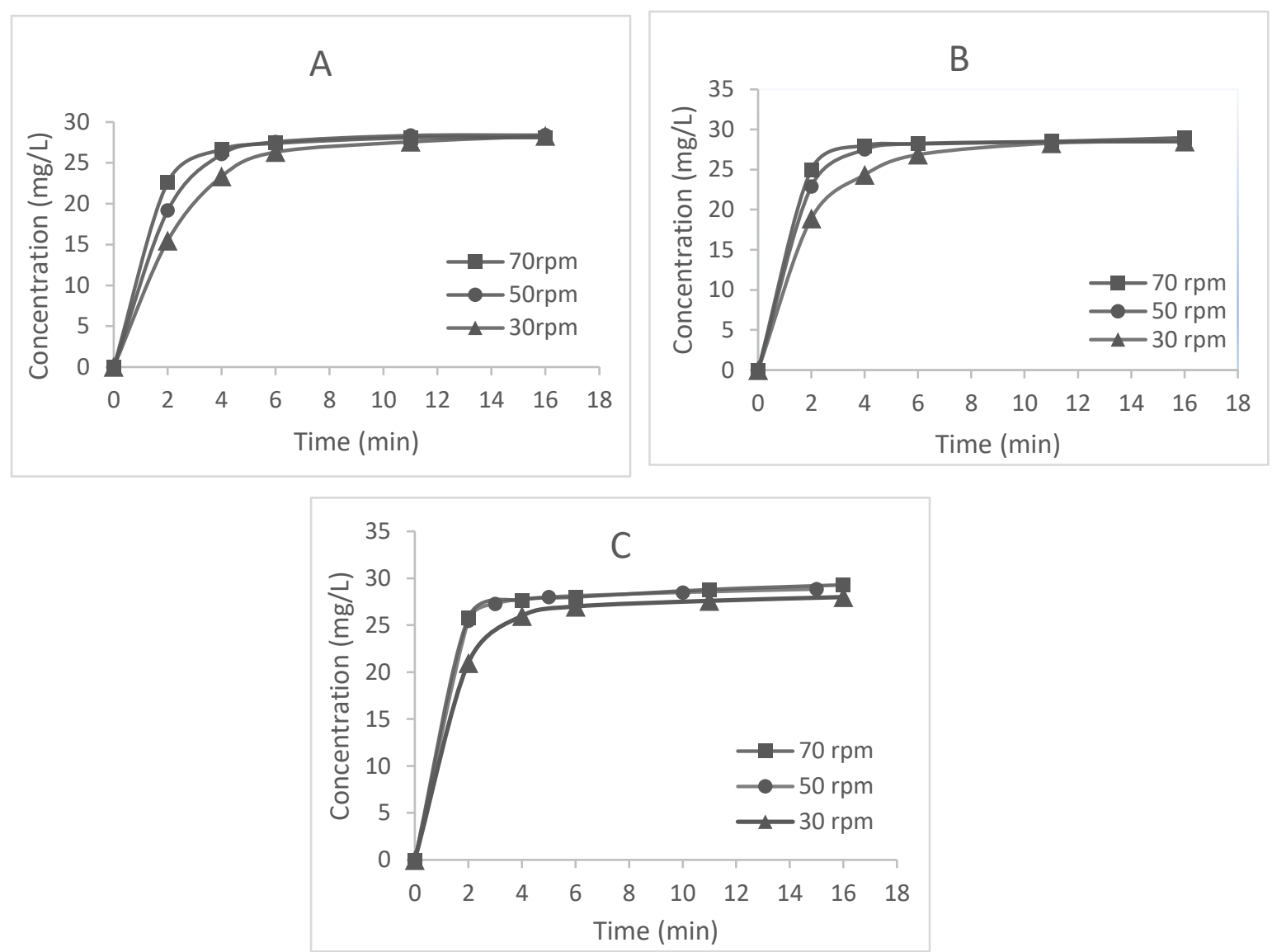

Fig. 6 Dissolution of naphthalene at different roller speed rotation (A) 30\% load, (B) 40\% load, and (C) $50 \%$ load. Naphthalene concentration $300 \mathrm{mg} / \mathrm{L}$ and, glass bead size $6 \mathrm{~mm}$

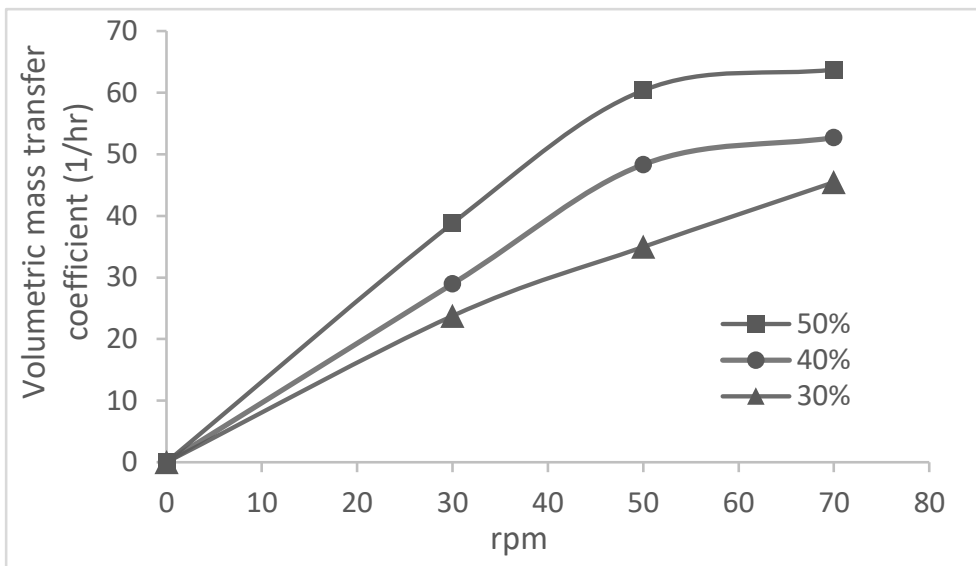

Fig.7 Dependency of volumetric mass transfer coefficient on roller speed rotation at different glass bead loading. Naphthalene concentration $300 \mathrm{mg} / \mathrm{L}$ and $6 \mathrm{~mm}$ size of glass beads 

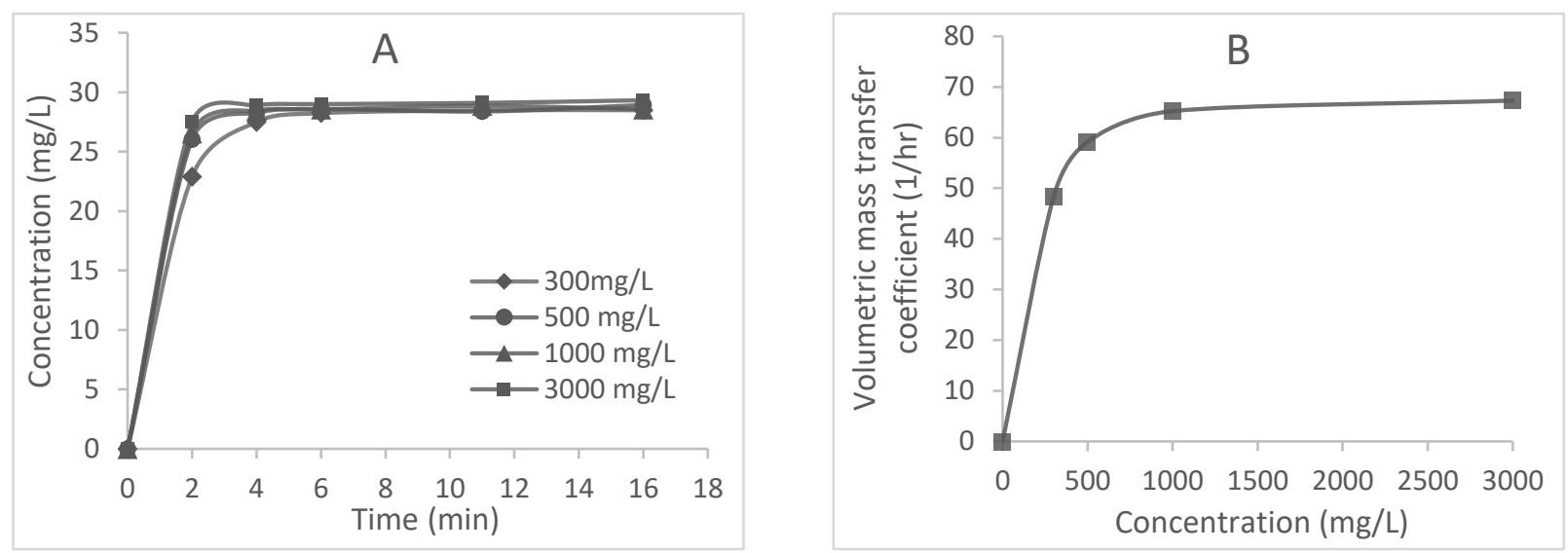

Fig. 8 (A) Dissolution of naphthalene at different concentration, (B) dependency of volumetric mass transfer coefficient on naphthalene concentration, at $40 \%$ load, $6 \mathrm{~mm}$ size of glass beads, and roller speed rotation 50rpm

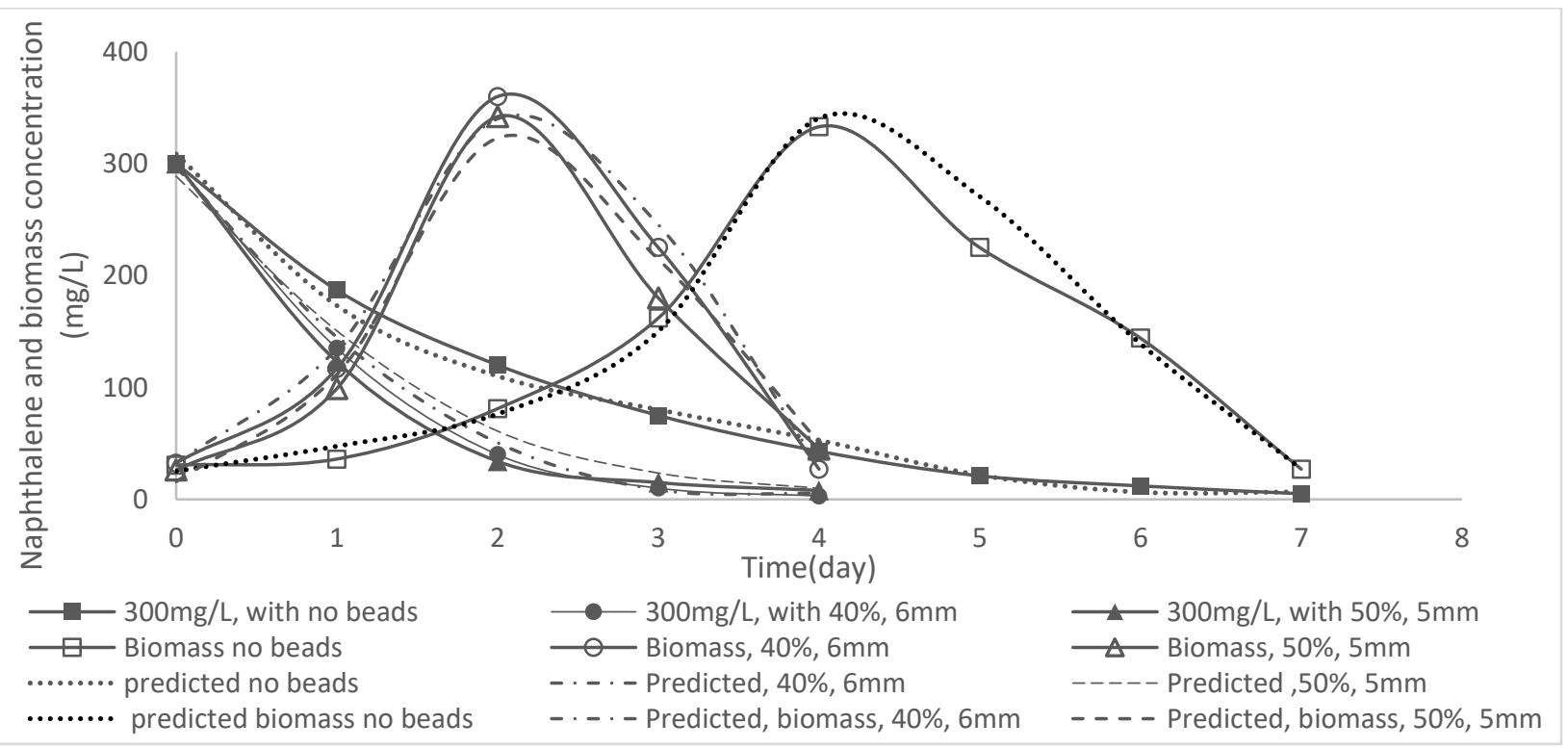

Fig. 9 Naphthalene and biomass concentration against the time of incubation at 300mg/L naphthalene with different loads and beads size. Experimental and predicted results 


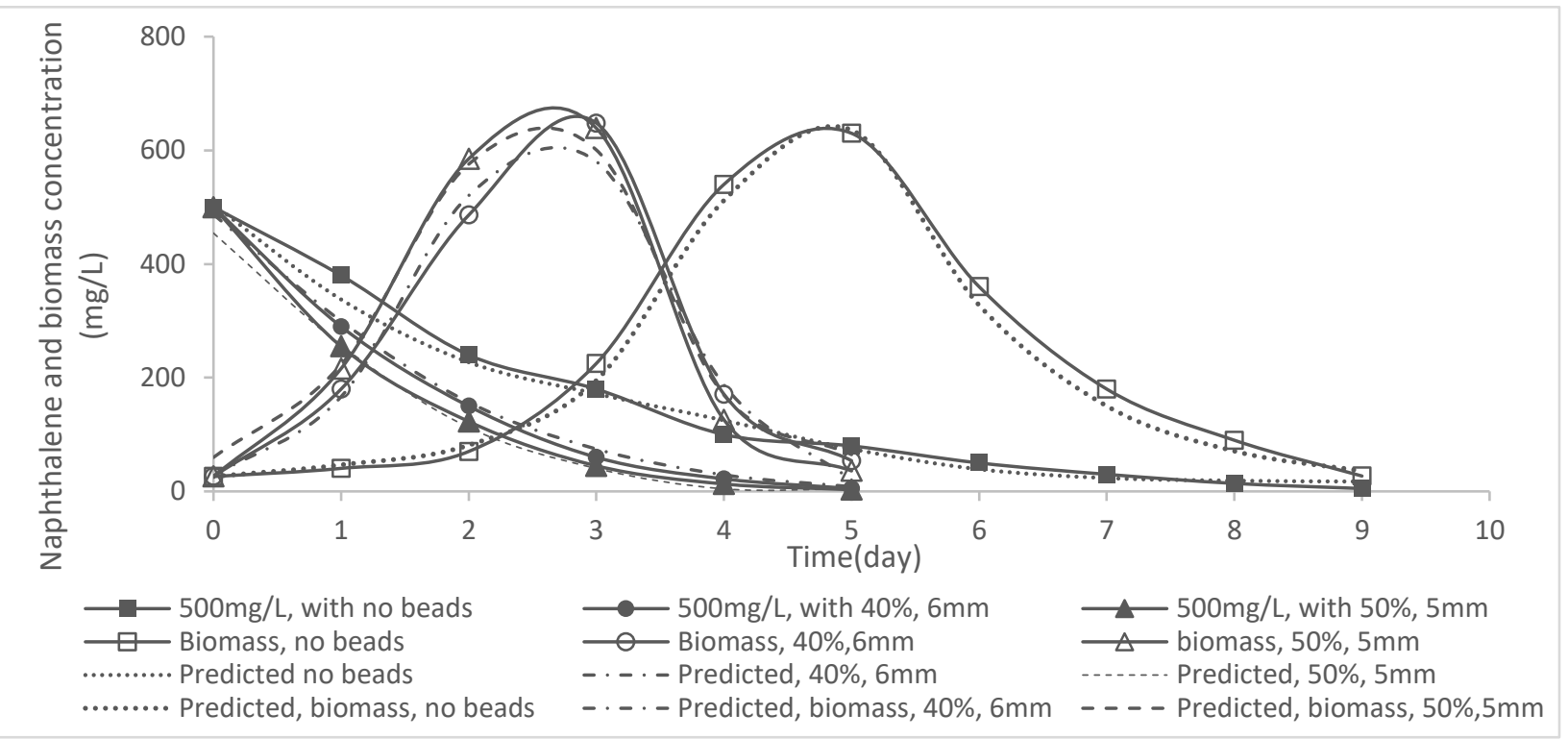

Fig. 10 Naphthalene and biomass concentration against a time of incubation at 500mg/L naphthalene with different loads and beads size. Experimental and predicted results 

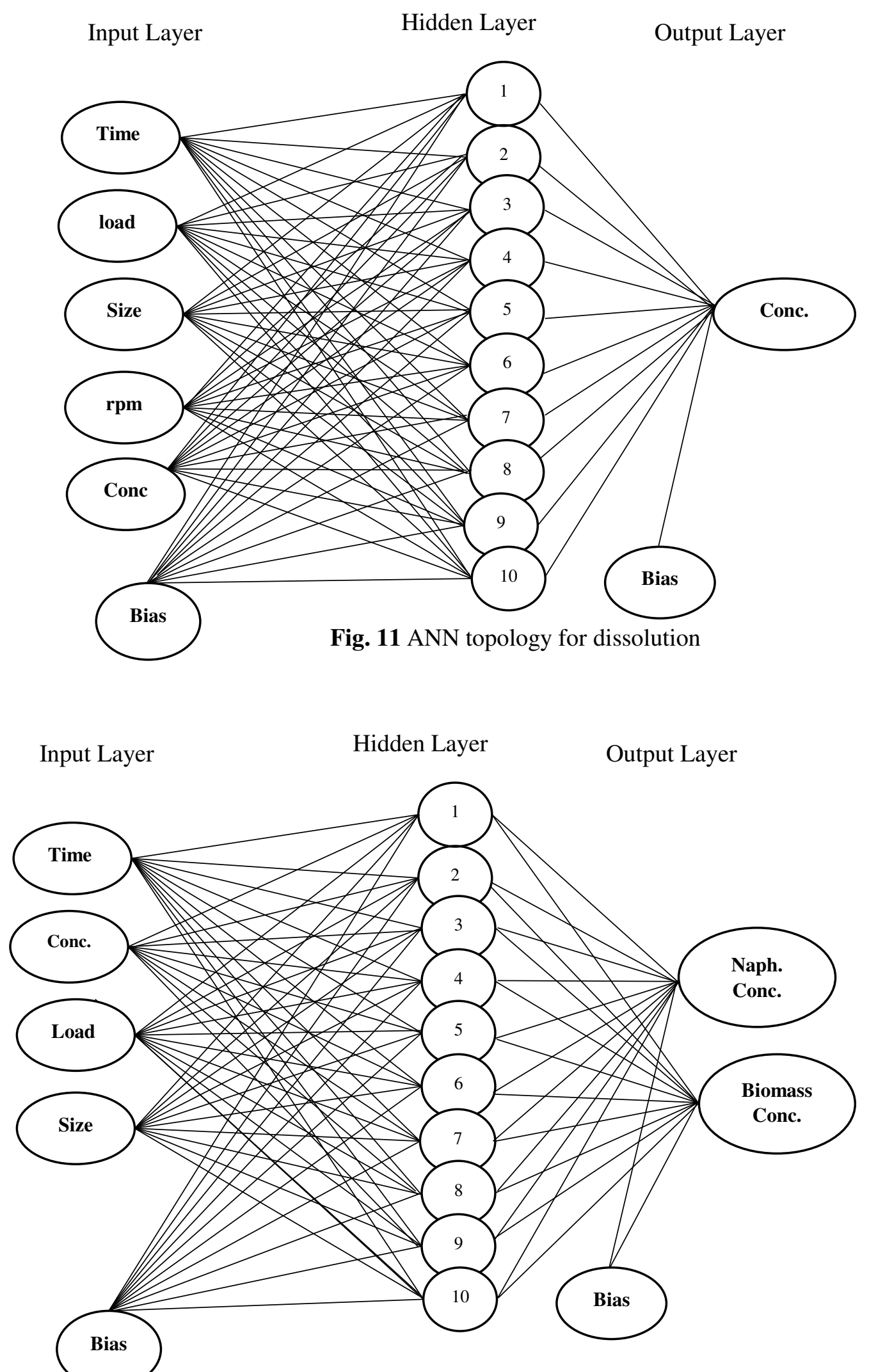

Fig. 12 ANN topology for biodegradation 


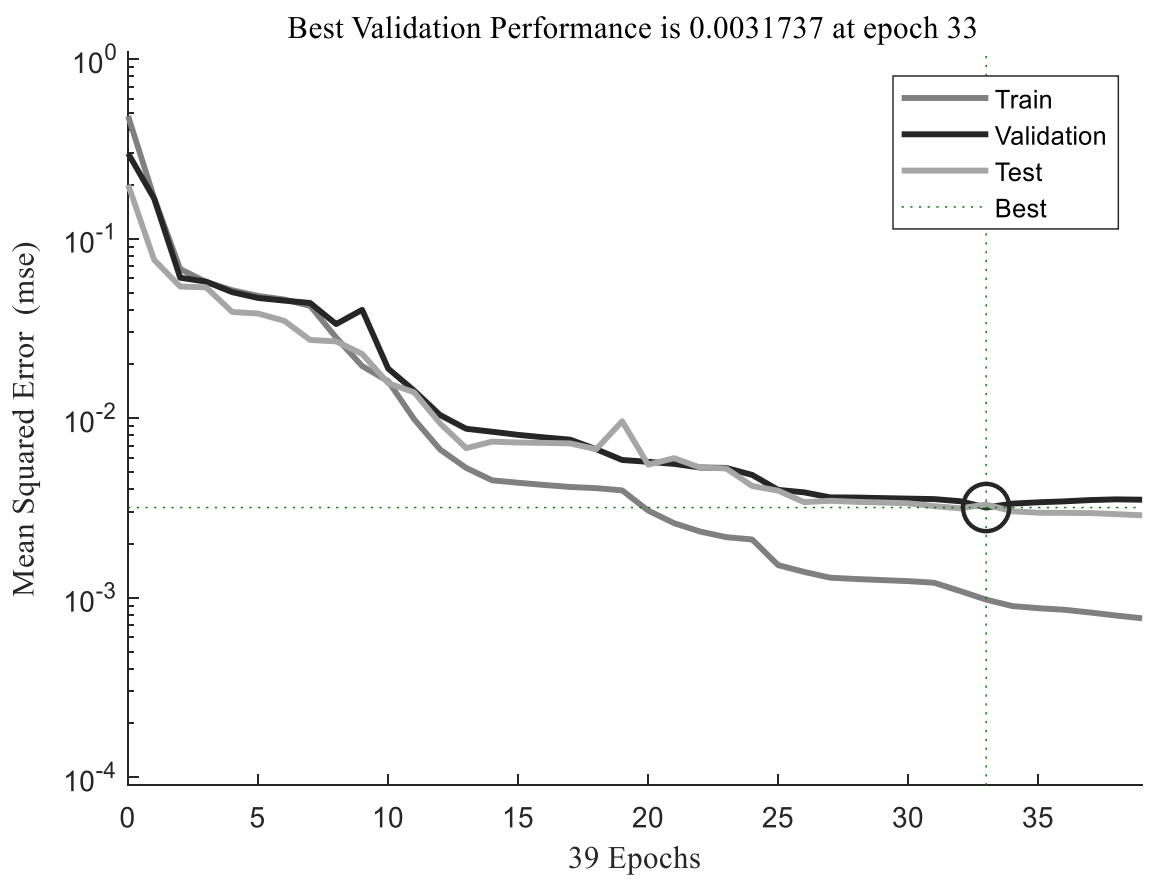

Fig. 13 Network training performance for dissolution data 

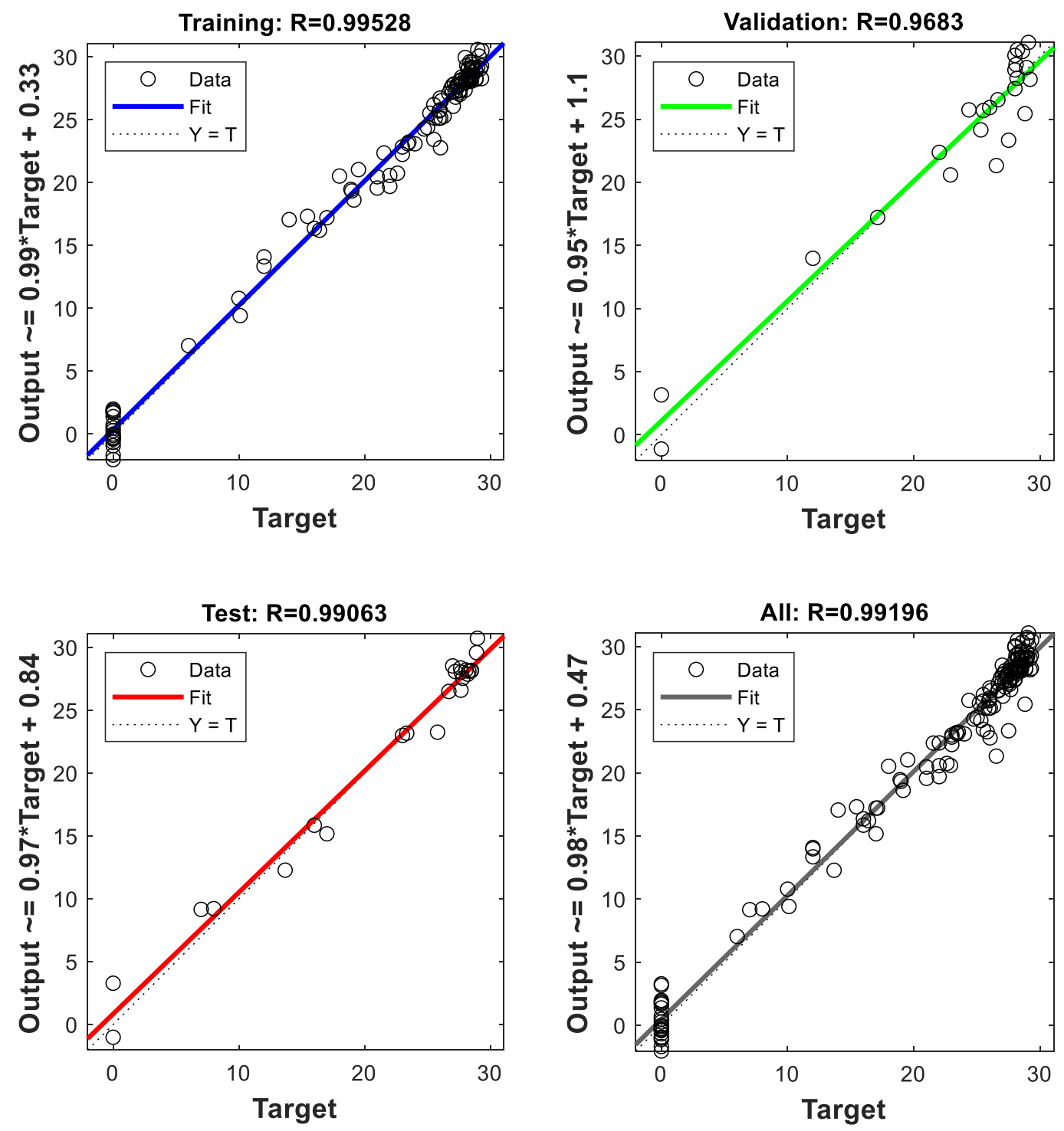

Fig. 14 Network training regressions for dissolution data 


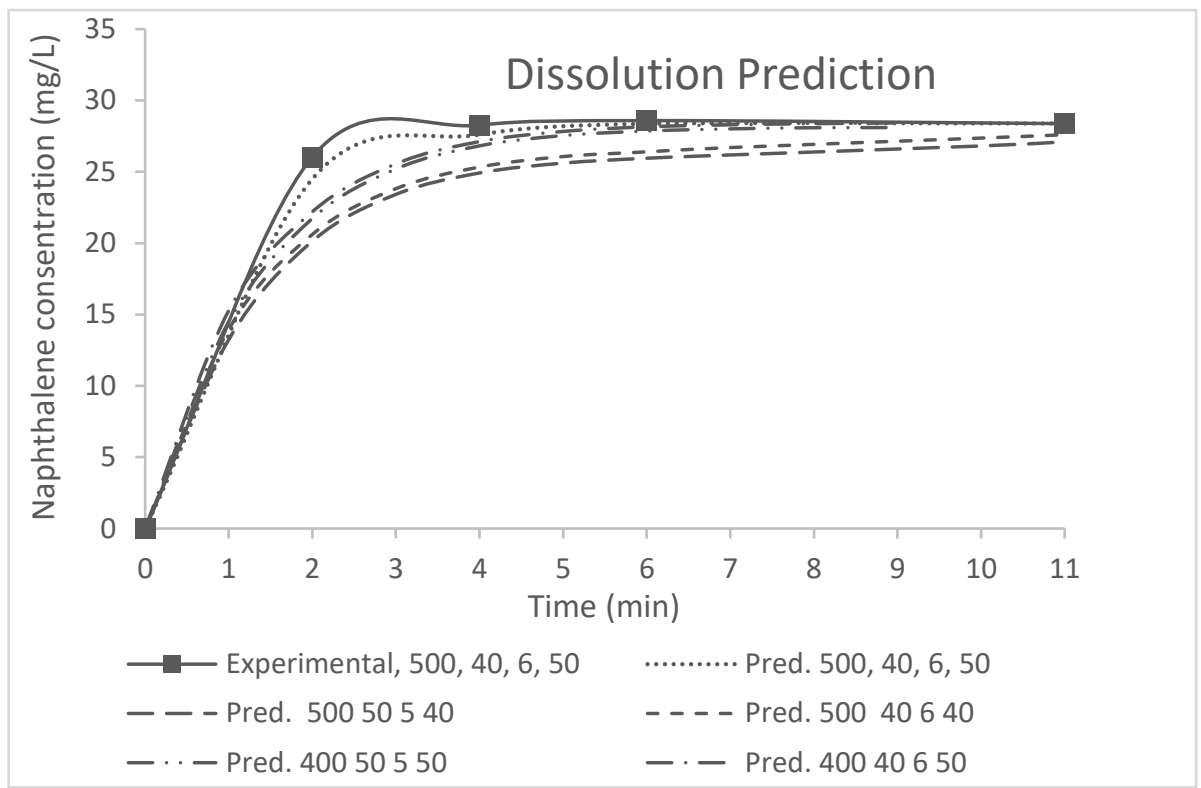

Fig.15 ANN predicted values for naphthalene dissolution 


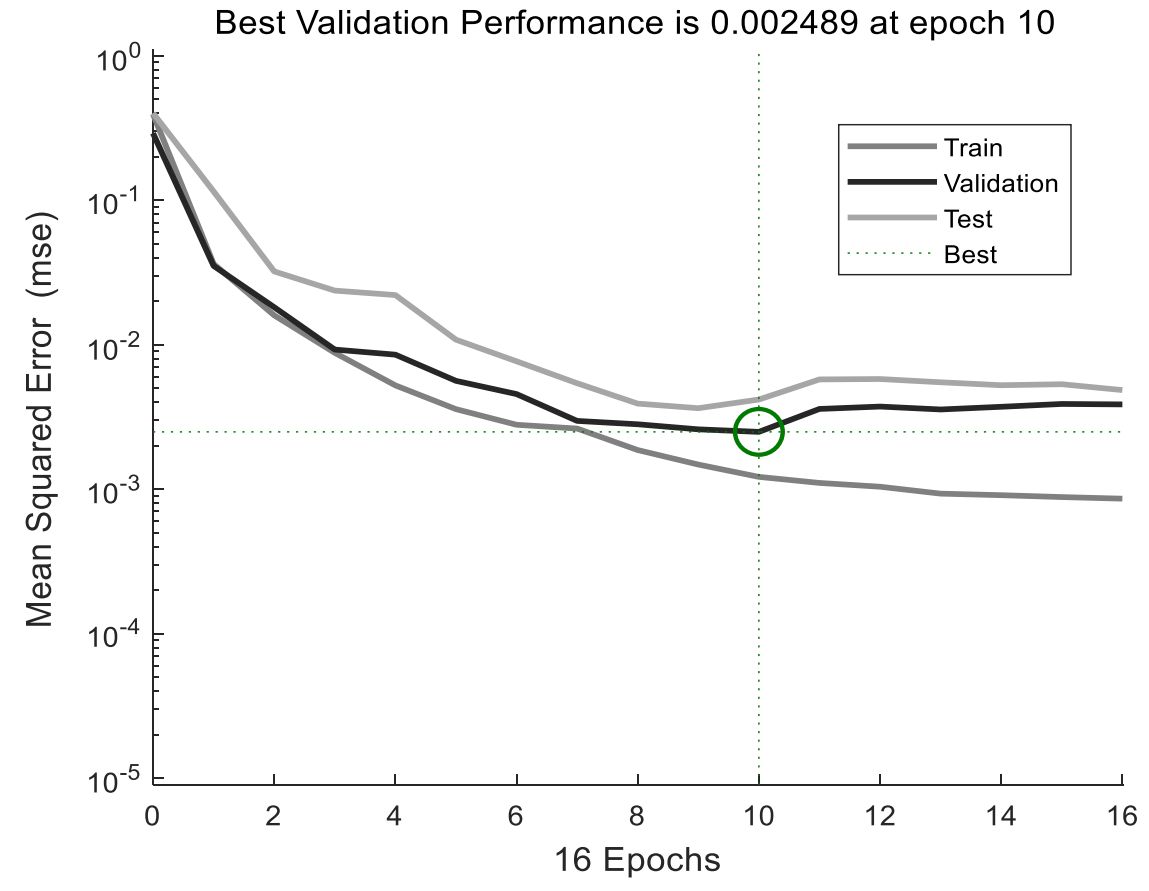

Fig.16 Network training performance for biodegradation data 

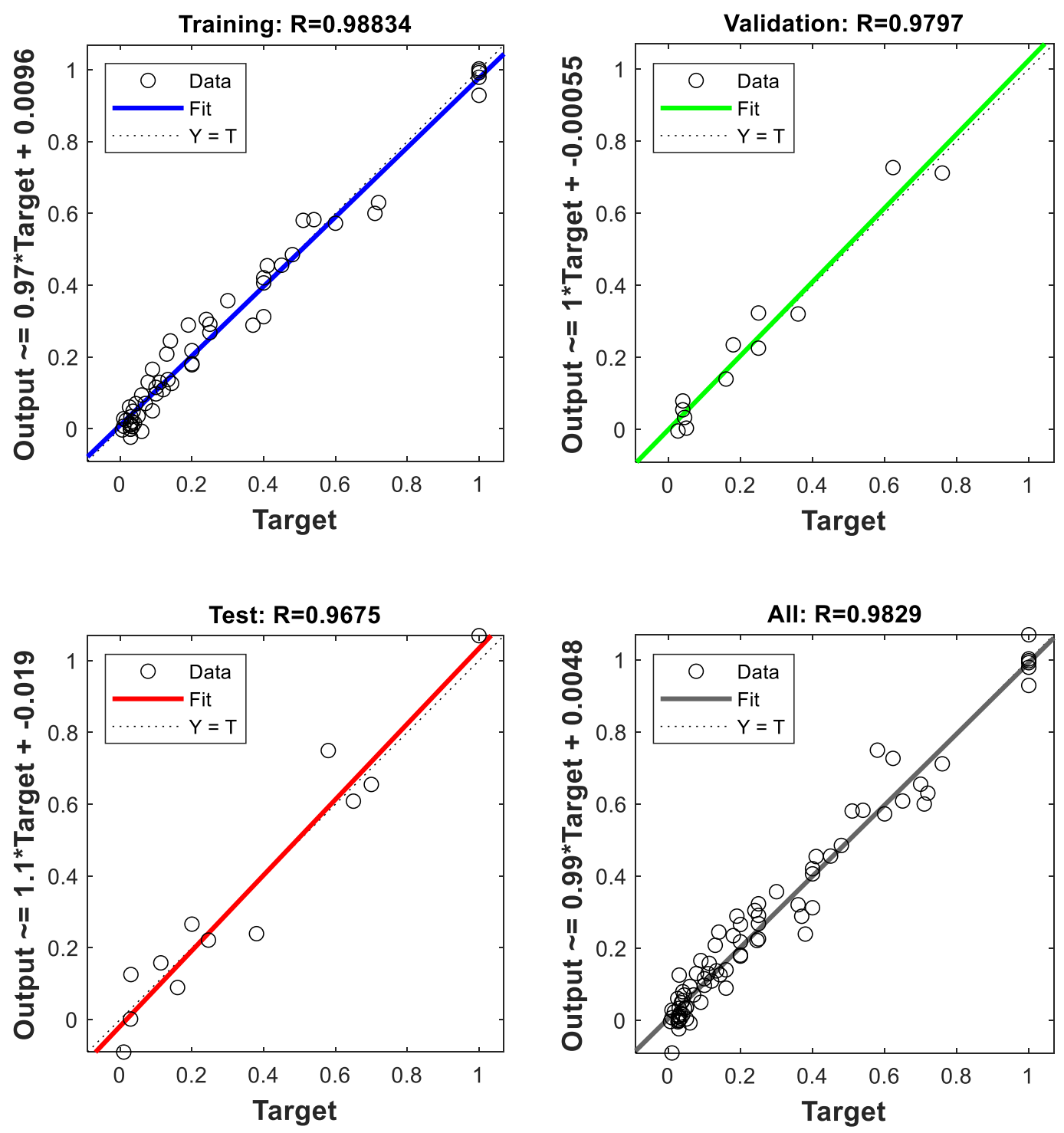

Fig.17 Network training regression for biodegradation data 


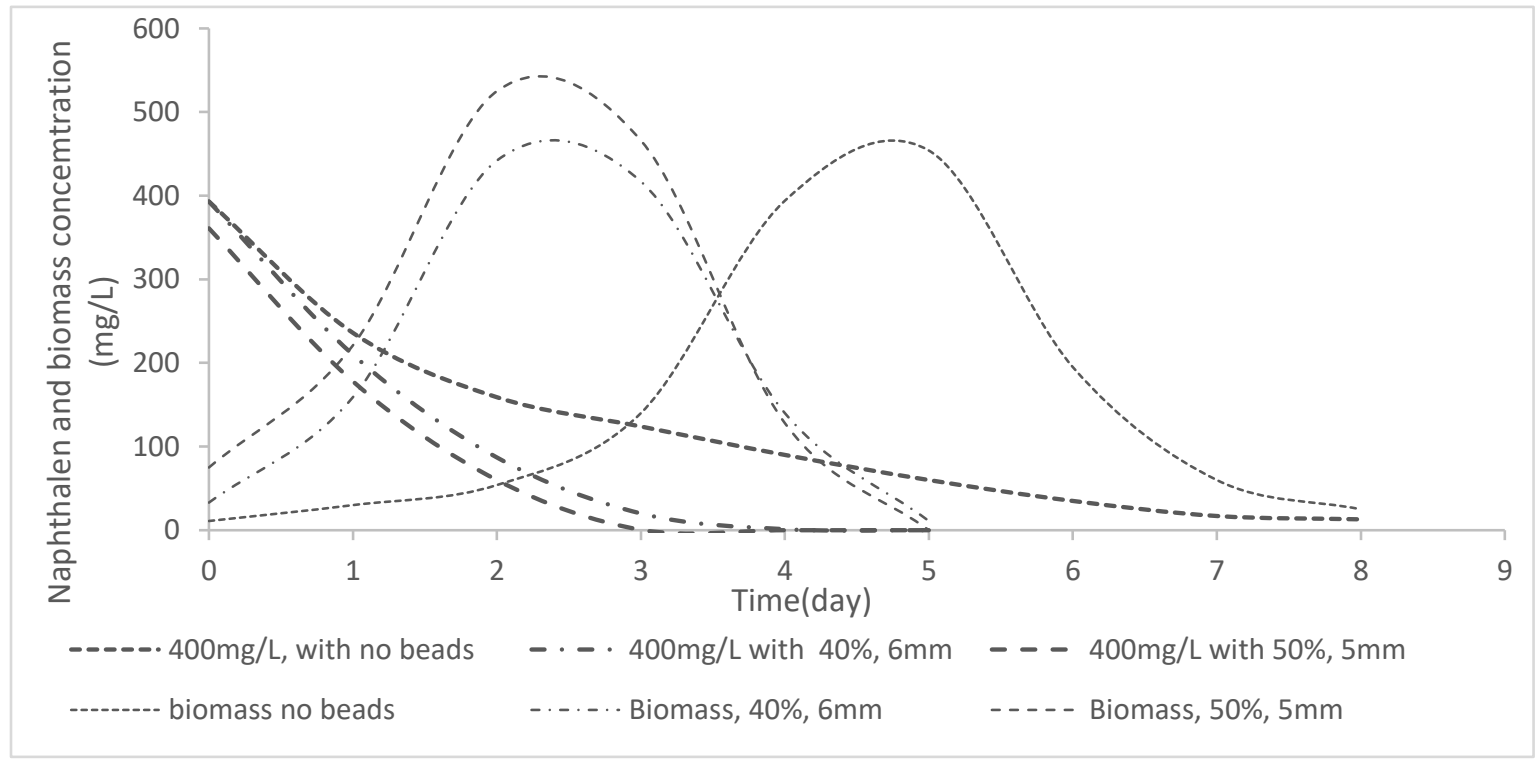

Fig.18 ANN predicted values for naphthalene biodegradation 


\section{Supplementary Files}

This is a list of supplementary files associated with this preprint. Click to download.

- datafortherollerresearch.xlsx 